\title{
Propagação Assimétrica de Choques Monetários na Economia Brasileira: Evidências com Base em um Modelo Vetorial Não-Linear de Transição Suave*
}

\author{
Vinícius dos Santos Cerqueira, Márcio Bruno Ribeiro, Thiago \\ Sevilhano Martinez $z^{\dagger}$
}

Conteúdo: 1. Introdução; 2. Revisão de literatura; 3. Análise preliminar: descrição das séries utilizadas; testes de raiz unitária; e especificação do modelo vetorial linear; 4. Especificação do modelo de transição suave; 5. Resultados quanto às estimativas dos parâmetros; 6. Resultados das funções de resposta a impulso; 7. Considerações Finais; A. Apêndice A - Figura A.1; B. Apêndice A2 - Tabela A.2; C. Apêndice A3 - Tabela A.3.

Palavras-chave: Assimetria; Política Monetária; Modelos Autoregressivos de Transição Suave.

Códigos JEL: $\quad$ E32; E52; C32; C52.

O trabalho busca aprofundar as investigações empíricas relacionadas aos efeitos assimétricos de choques monetários na economia brasileira. Como instrumental de análise, utiliza-se um modelo vetorial não linear de transição suave para variáveis relacionadas ao produto, às taxas de inflação e de câmbio e ao indicador de política monetária. As funções de resposta a impulso estimadas apontaram que choques monetários expansionistas e contracionistas têm efeitos assimétricos sobre o crescimento do produto e a inflação. Quanto ao ciclo econômico, choques monetários contracionistas mostraram maior impacto em regimes de menor crescimento ou inflação baixa, enquanto os choques expansionistas predominaram em períodos de maior crescimento ou inflação alta. Ademais, evidencia-se a rigidez da inflação e do crescimento do produto aos choques contra cíclicos.

This paper attempts to extend empirical investigations about the asymmetric effects of monetary shocks in the Brazilian economy. We specify and estimate a nonlinear smooth transition vector autoregressive model

\footnotetext{
* Os autores agradecem: a Charles Weise e a Nathan Balke, pelo envio dos códigos de programação relativos à estimativa e inferência de modelos vetoriais não-lineares; e aos comentários e sugestões do parecerista (anônimo) que avaliou uma versão anterior do trabalho. Os erros remanescentes são de responsabilidade dos autores.

† Técnicos de Planejamento e Pesquisa da Diretoria de Estudos e Políticas Macroeconômicas (Dimac) do Ipea. E-mails para contato: vinicius.cerqueira@ipea.gov.br, marcio.ribeiro@ipea.gov.br, thiago.martinez@ipea.gov.br
} 
including output, inflation, exchange rate and a monetary policy indicator (SELIC rate). Impulse response functions showed that expansionary and contractionary monetary shocks have asymmetric effects on output growth and inflation. Regarding to the business cycle, contractionary monetary shocks showed stronger effects in both low-growth and low-inflation states, while expansionary shocks were stronger in both higher-growth and higherinflation periods. In addition, we found that inflation and output growth are rigid to countercyclical monetary shocks.

\section{INTRODUÇÃO}

O debate sobre a assimetria dos efeitos da política monetária expansionista e contracionista, em booms e recessões, remonta ao período da grande depressão na década de 30. Perpassando as controvérsias entre keynesianos e monetaristas sobre a eficácia da política monetária, o tema voltou a ganhar força nos anos 80, com a dificuldade da economia americana para sair da estagnação. Desde Cover (1992), vem se desenvolvendo ampla literatura internacional empírica sobre efeitos assimétricos da política monetária no produto e, em menor medida, nos preços.

Para o caso da economia brasileira, o estudo de Aragón e Portugual (2009) é o único na literatura recente a investigar os efeitos assimétricos da política monetária sobre o produto no período posterior ao Plano Real. Utilizando a estimativa de modelos Markov-Switching para a taxa de crescimento do produto, o trabalho evidenciou que os efeitos reais de choques monetários contracionistas são superiores aos efeitos de choques expansionistas apenas em regimes de aumento da atividade econômica. Por outro lado, as evidências encontradas não foram suficientes para comprovar a presença de assimetrias relacionadas às fases do ciclo de negócios e com relação aos efeitos contra cíclicos da política monetária nestas fases.

O presente trabalho tem por objetivo aprofundar as investigações empíricas relacionadas aos efeitos assimétricos da política monetária na economia brasileira. Para isso, seguiremos de perto a metodologia utilizada em Weise (1999), tendo como instrumental de análise um modelo vetorial não linear de transição suave para variáveis relacionadas ao produto, às taxas de inflação e câmbio e ao indicador de política monetária. As funções de resposta a impulso geradas pelo modelo estimado permitirão verificar diretamente os efeitos de choques monetários sobre as demais variáveis. Além de revisitar as evidências de assimetrias relacionadas à direção das ações de política monetária - choques expansionistas versus contracionistas - e à fase do ciclo de negócios em que tais ações foram adotadas, nossa análise permitirá investigações de assimetria quanto à magnitude dos choques monetários - choques relativamente maiores versus relativamente menores -, algo ainda não averiguado para a economia brasileira. Além disso, será possível investigar os efeitos assimétricos da política monetária não apenas em relação ao comportamento do produto, mas também em relação à taxa de inflação.

O trabalho está organizado em seis seções, sendo a primeira esta introdução. A segunda seção é uma revisão da literatura sobre efeitos assimétricos de choques monetários. A terceira parte apresenta uma análise preliminar à especificação do modelo principal, descrevendo brevemente as principais características das séries utilizadas, o horizonte temporal considerado e o modelo vetorial linear (benchmark). A quarta seção discute os principais aspectos da etapa referente à especificação de um modelo de transição suave entre os regimes, apresentando os resultados obtidos quanto às definições das variáveis de transição e da forma de sua função. Na quinta parte são apresentados os principais resultados quanto à estimativa dos parâmetros e à avaliação das especificações obtidas. A sexta seção discute os resultados referentes às funções de resposta a impulso geradas a partir das especificações selecionadas, evidenciando os principais tipos de assimetria encontrados em relação aos choques monetários. A última seção do trabalho é destinada às considerações finais. 


\section{REVISÃO DE LITERATURA}

Diferentes tipos de respostas assimétricas do produto e dos preços à política monetária podem resultar de não linearidades nas relações entre essas variáveis. A forma mais testada empiricamente é a referente à sua direção, ou seja, se choques monetários expansionistas têm o mesmo impacto de choques contracionistas. Ravn e Sola (2004) denominam esse tipo de não linearidade de "assimetria keynesiana”. Ela é justificada teoricamente por hipóteses de salários nominais e preços mais rígidos à baixa que à alta, que resultam em uma curva de oferta agregada convexa.

Para os EUA, com período amostral de 1951:1 a 1987:4, Cover (1992) utiliza M1 como variável de política monetária e conclui que apenas choques monetários negativos (contracionistas) impactam significativamente o produto. O mesmo resultado é encontrado por DeLong e Summers (1988), que utilizam um período mais longo, e questionado por Ravn e Sola (1996), que conduzem testes de robustez. Morgan (1993) também replica a metodologia de dois estágios de Cover (1992) e observa que os resultados são sensíveis a mudanças nas medidas de oferta de moeda e períodos amostrais. Quanto a outros países, é verificado que contrações monetárias são mais efetivas que expansões em países europeus por Karras (1996), em 12 países da OCDE por Karras (2007) e em quatro países asiáticos por Tan et alii (2010).

A rigidez de preços pode ainda gerar outros tipos de assimetrias, como a referente à magnitude dos choques. Em uma curva de oferta agregada convexa no formato de "L invertido", com um trecho aproximadamente horizontal e outro vertical, choques pequenos de sinais opostos serão simétricos se não implicarem em mudança de um trecho para outro, enquanto choques grandes têm mais chance de causar a mudança. Os modelos de custos de menu (como Ball e Mankiw, 1994), por sua vez, conferem microfundamentos à rigidez de preços considerando que cada firma precisa pagar um custo para ajustar seus preços, o que faz com que o ajuste da economia a choques menores seja mais lento que o ajuste a choques maiores. Surge então a assimetria de acordo com a magnitude do choque monetário: choques grandes têm efeitos proporcionalmente maiores sobre os preços e choques menores afetam proporcionalmente mais o produto. Ravn e Sola (1996) e Donayre (2010) encontram evidência corroborando esse tipo de assimetria para os EUA. O modelo de Ball e Mankiw (1994) mostra que, se além de custos de menu a economia também tem uma tendência inflacionária positiva, as firmas serão mais relutantes em reajustar preços para baixo do que para cima, uma vez que no primeiro caso a inflação positiva tende a corrigir seu preço relativo sem que seja necessário pagar o custo de reajuste. De acordo com Ravn e Sola (2004), esse modelo gera uma "assimetria híbrida" dos dois tipos anteriores, em que apenas choques pequenos e negativos afetam o produto, sendo que o estudo empírico dos autores aponta para a validade dessa hipótese nos EUA. Karras (2007) observa que, particularmente para choques negativos, a efetividade da política monetária é uma função decrescente do tamanho do choque. Senda (2001) deriva outros dois resultados teóricos do modelo de Ball e Mankiw (1994) - que taxas de inflação a partir de certo nível podem reduzir a assimetria e que quanto maior a volatilidade do produto, maior a assimetria - e verifica que ambos têm suporte em dados da OCDE.

Também é bastante testada na literatura uma forma de assimetria referente ao estágio do ciclo econômico, que pode ser explicada tanto por convexidade na oferta agregada quanto por instabilidade no canal de transmissão da política monetária para a demanda agregada. Sobre uma curva de oferta agregada com formato convexo, choques monetários terão mais efeitos reais na região de baixo crescimento do produto e mais efeitos em preços na região de alto crescimento do produto. Já as teorias sobre alterações ao longo do ciclo na transmissão dos choques monetários à demanda agregada podem implicar em diferentes resultados. As formas mais recorrentes dessas teorias são a mudança de ambiente econômico e o acelerador financeiro. Segundo a primeira, a elevação da incerteza na recessão e o otimismo exacerbado na expansão afetam a eficácia da política monetária. Geralmente essa teoria é utilizada para explicar contextos de armadilha da liquidez, quando em recessões a política monetária anticíclica é pouco efetiva porque a incerteza eleva a preferência pela liquidez de empresas e consumidores a tal ponto que reduções de juros têm pouco ou nenhum efeito. Como nota Morgan (1993), 
esse argumento só implica em assimetria de choques monetários anticíclicos negativos e positivos se o pessimismo na recessão é mais intenso que o otimismo na expansão.

As explicações desse tipo de assimetria pelo comportamento do crédito baseiam-se em teorizações sobre o mecanismo do canal de crédito da política monetária. Nos modelos de acelerador financeiro, como Bernanke e Gertler (1995) e Bernanke et alii (1996), a política monetária tem seus efeitos amplificados ao afetar a disponibilidade de recursos para o crédito e a valoração patrimonial dos agentes. Cabe notar que, no plano teórico, o acelerador financeiro amplifica os resultados da política monetária, mas só irá gerar assimetria se for mais potente em uma das fases do ciclo. Com um painel de microdados de firmas americanas, Gertler e Gilchrist (1994) e Bernanke et alii (1999) observam que pequenas empresas sofrem maior restrição de crédito que as grandes empresas nas recessões - justamente quando mais necessitam de recursos externos - e respondem reduzindo sua produção e demitindo mais que as grandes. Já nas expansões, há maior disponibilidade de recursos próprios para as firmas se financiarem e a restrição de crédito não é tão ativa quanto na recessão, de maneira que o ajuste é semelhante nas pequenas e grandes. Haveria então uma assimetria nos efeitos da política monetária, que seria mais eficaz em recessões do que em expansões.

Testes de assimetria quanto ao estágio do ciclo econômico para a economia americana apontam maior efetividade da política monetária nas recessões. Para as décadas de 60 a 80, Thoma (1994) observa que a causalidade moeda-produto é mais forte nos períodos de recessão. Garcia e Schaller (2002) também encontram efeitos da política monetária sobre o produto mais intensos na recessão, com testes de robustez para troca de variável monetária, da marcação das fases do ciclo, período amostral, frequência dos dados e especificação econométrica. Lo e Piger (2005), testando conjuntamente a possibilidade de assimetria do choque monetário quanto à direção, magnitude e fase do ciclo, encontram que a última é a única forma de assimetria relevante para os EUA, com maior eficácia da política monetária na recessão. Um maior impacto da política monetária nas recessões ou em períodos de baixo crescimento também é observado para diversos países europeus - Alemanha, França, Itália, Espanha, Bélgica e, com fraca significância, Áustria e Holanda (Peersman e Smets, 2005) - e asiáticos - Indonésia, Malásia, Filipinas e Tailândia (Hooi et alii, 2008).

Para o Brasil, Aragón e Portugual (2009) testam dois tipos de assimetria de efeitos da política monetária sobre o produto, com dados mensais de 1995 a 2006: quanto à direção dos choques monetários (positivos e negativos) e em relação à fase do ciclo econômico (recessão e expansão). Encontram que há assimetria referente à direção da política monetária apenas quando a economia está em expansão, com choques negativos afetando mais o produto, sendo que na recessão não há assimetria entre choques positivos e negativos. Mas comparando diretamente as fases do ciclo, não verificam assimetria de impactos na recessão e na expansão. Em particular, políticas anticíclicas são simétricas nas duas fases.

A grande maioria dos artigos mencionados mede efeitos assimétricos da política monetária sobre o produto, mas não sobre os preços. Como argumentam Karras e Stokes (1999), isso seria necessário para confrontar com dados agregados as duas formas mais gerais de explicações teóricas da propagação assimétrica de choques monetários, convexidade da oferta agregada e canais de transmissão da moeda. ${ }^{1}$ A assimetria originada na curva de oferta convexa implica efeitos opostos em preços e quantidades, ou seja, quando uma dessas variáveis é rígida, a outra é flexível. Por outro lado, se a assimetria estiver relacionada ao canal de transmissão da moeda para a demanda agregada, preços e quantidades são afetados na mesma direção. Karras e Stokes (1999) encontram forte assimetria na resposta do produto a choques positivos e negativos, mas sobre preços os impactos são praticamente simétricos, o que interpretam como indicativo de que as duas teorias são válidas simultaneamente.

Quanto ao procedimento econométrico, é de uma equação nos primeiros textos sobre o tema, como Cover (1992), Morgan (1993) e Thoma (1994). Há um estágio prévio que consiste em estimar uma

\footnotetext{
${ }^{1}$ Alguns artigos, como Gertler e Gilchrist (1994) e Peersman e Smets (2005), comparam as teorias sobre propagação assimétrica da política monetária a partir de dados desagregados de produção, preços e estrutura de financiamento e outras informações de empresas e setores. Esse debate foge ao escopo do presente artigo, que investiga apenas dados agregados.
} 
equação com a política monetária como variável dependente para identificar os choques monetários exógenos, que são os resíduos. As observações positivas e negativas dos choques monetários assim identificados são separadas em duas variáveis, que entram como regressoras na estimação da equação em forma reduzida que tem o produto como variável dependente. A existência de assimetria é verificada testando restrições sobre os coeficientes dessas duas variáveis de choques monetários. De acordo com Weise (1999), isso implicitamente equivale a supor que o choque monetário é uma variável com um threshold, ou seja, a passagem da variável monetária exógena de positiva para negativa ou viceversa leva o sistema para outro estado em que muda a resposta do produto aos choques monetários. $\mathrm{O}$ autor aponta um problema nessa metodologia: embora os coeficientes da resposta do produto aos choques monetários mudem com a troca de regime, os coeficientes dos outros regressores na equação do produto permanecem os mesmos, o que equivale a impor uma restrição demasiadamente forte.

Para contornar esse problema, Weise (1999) adota um modelo de vetores auto regressivos com transição suave (TSVAR), que permite variar todos os parâmetros do modelo referentes a cada estado. 0 autor testa as três hipóteses de assimetria no efeito dos choques monetários - direção, fase do ciclo e magnitude. Ademais, a partir das propriedades do modelo TSVAR, os testes sobre assimetria são generalizados em outros aspectos: verificar a possibilidade de diversas variáveis portarem o threshold que leva à mudança de estado, determinar endogenamente o valor do threshold e permitir que a mudança de regime seja suave, ao invés de imediata após o threshold ser ultrapassado.

Alguns autores - como Garcia e Schaller (2002), Peersman e Smets (2002) e Lo e Piger (2005) adotam versões aprimoradas do modelo de mudança de regimes markovianos de Hamilton (1989) que incorporam boa parte desses avanços, como permitir a alteração de todos os coeficientes na troca de regime, testar diferentes variáveis de transição e a determinação endógena da passagem entre regimes via endogeinização das probabilidades de transição. O método aplicado aos dados brasileiros por Aragón e Portugal (1999) é uma versão desse modelo com probabilidades de transição fixas. Comparativamente ao TSVAR de Weise (1999), o modelo de mudança de regimes markovianos tem duas desvantagens. A mais óbvia é que impõe que as mudanças de regimes são repentinas. A outra é que a determinação da variável monetária não é endógena, o que geralmente é contornado com um estágio prévio de identificação dos choques monetários por um VAR linear. Esse procedimento reintroduz em alguma medida a crítica de Weise, pois não leva em conta a realimentação do produto ao choque monetário por um canal não linear.

Weise (1999) encontra para os EUA evidências consistentes com a hipótese de convexidade da curva de oferta: choques monetários em qualquer direção afetam bastante o produto e pouco os preços quando o estado inicial é de baixo crescimento do produto, o inverso ocorrendo se o estado inicial é de alto crescimento; os efeitos de choques pequenos são quase simétricos, enquanto os choques grandes podem ter forte assimetria. Seguindo essa forma de análise, o presente estudo aplica ao caso brasileiro o modelo TSVAR, testando as três hipóteses de assimetria de efeitos da política monetária - direção, magnitude e fase do ciclo - sobre o produto e os preços. Como em Weise (1999), diferentes variáveis de transição são testadas e a determinação dos valores dos threshold é endógena.

\section{ANÁLISE PRELIMINAR: DESCRIÇÃO DAS SÉRIES UTILIZADAS; TESTES DE RAIZ UNITÁ- RIA; E ESPECIFICAÇÃO DO MODELO VETORIAL LINEAR}

Nesta seção, descreveremos brevemente as séries utilizadas e alguns procedimentos adotados visando à especificação de um modelo vetorial linear (modelo base ou benchmark), que será posteriormente confrontado com um modelo não linear de transição suave. Seguindo a literatura referente à assimetria dos choques monetários, as principais variáveis incluídas nos modelos empíricos são relativas ao produto, à inflação e a um indicador monetário. Além disso, e com base em alguns estudos que avaliaram empiricamente os principais impactos da política monetária na economia brasileira em períodos posteriores à adoção do Plano Real - Moreira et alii (1998), Arquete e Jayme Jr. (2003), Céspedes 
et alii (2008), Mendonça et alii (2010), Lima et alii (2011) -, decidimos também pela inclusão de uma variável relativa ao câmbio, de forma a captar possíveis interações com o setor externo.

No caso do produto, utilizamos como aproximação a série do índice de produção industrial com ajuste sazonal, que é divulgada na Pesquisa Industrial Mensal (PIM) do Instituto Brasileiro de Geografia e Estatística (IBGE). Como medida da inflação, foi utilizada a variação percentual mensal do Índice Nacional de Preços ao Consumidor Amplo (IPCA) dessazonalizado, série divulgada pelo IBGE. ${ }^{2}$ Para o indicador monetário, utilizamos a série da taxa SELIC (taxa de juros de curto-prazo, acumulada no mês e medida em \% ao ano), que é divulgada pelo Banco Central do Brasil (BACEN) e pode ser considerada como a principal variável de política monetária desde que o regime de metas para a inflação foi adotado na economia brasileira. ${ }^{3}$ Como medida cambial, utilizamos a taxa para compra do dólar americano (média do mês), cuja fonte é o BACEN. Todas as séries de dados utilizadas têm frequência mensal e, com base nos procedimentos operacionais de política monetária adotados desde a estabilização alcançada com o Plano Real, podem ser conjuntamente analisadas em termos econométricos a partir de julho de 1999. ${ }^{4}$ Assim, decidimos por estabelecer este mês como o primeiro de nossa análise, com extensão até dezembro de 2012, num total de 162 observações para cada série. Os gráficos das séries mencionadas, além da variação da SELIC e das variações percentuais do índice de produção industrial e da taxa de câmbio, estão apresentados na figura A.1 do Apêndice para o período considerado.

A inspeção visual dos gráficos nos permite evidenciar algumas mudanças na estrutura das séries em nível e a presença de outliers nas séries em variações. A produção industrial e a taxa de câmbio são caracterizadas por variações abruptas no quarto trimestre de 2008, atribuídas aos efeitos da crise financeira internacional sobre a economia brasileira a partir do final daquele ano. A inflação medida pelo IPCA apresenta seus maiores valores entre o segundo semestre de 2002 e os primeiros meses de 2003. Em grande parte, este comportamento pode ser justificado pelo processo de desvalorização cambial iniciado em 2002 (notar que também ocorrem grandes variações na série do câmbio para aquele período), o qual foi motivado, em última instância, pelas incertezas quanto às diretrizes da política econômica diante da provável eleição, no pleito eleitoral do final do mesmo ano, de um governo com visão ideológica diferente do antecessor. A taxa SELIC aparenta uma tendência de queda em todo o período, mas caracterizada por rápidas elevações em intervalos de poucos meses.

Um dos principais problemas relacionados à presença de mudanças estruturais e outliers em uma série de tempo é quanto à incerteza na determinação da sua ordem de integração, com o possível viés dos resultados dos testes convencionais de raízes unitárias na direção de não se rejeitar a hipótese nula (Perron, 1989). Assim, como ponto de partida de nossa análise, a investigação quanto à ordem de integração de cada série foi realizada com a aplicação dos testes de raiz unitária propostos em Saikkonen e Lütkepohl (2002), que permitem considerar formas distintas para aquelas mudanças. ${ }^{5}$ A decisão sobre a forma mais adequada para a modelagem da quebra em cada série foi tomada com base na análise dos resíduos das equações estimadas. Os resultados obtidos estão apresentados na tabela 1.

\footnotetext{
${ }^{2} \mathrm{~A}$ escolha de séries com ajuste sazonal para o produto e a inflação buscou, principalmente, evitar que possíveis presenças de padrões sazonais constantes, e predominantes nas mesmas, encobrissem as evidências de não linearidade.

${ }^{3}$ Segundo Banco Central do Brasil (2010), no regime de metas para a inflação, a ação se baseia apenas no controle da taxa de juros de curto-prazo (SELIC), sem atribuição de metas adicionais para o câmbio ou o crescimento. Entretanto, essas e outras variáveis são levadas em consideração na construção do cenário prospectivo para a inflação.

${ }^{4}$ O mês de julho de 1999 é o primeiro no qual passou a vigorar integralmente o regime de metas para a inflação na economia nacional, quando ocorreram algumas mudanças operacionais importantes na condução da política monetária em relação ao início do Plano Real (veja, por exemplo, Lima et alii, 2007).

${ }^{5}$ Os testes propostos em Saikkonen e Lütkepohl (2002) admitem quatro possibilidades distintas para a mudança estrutural: dummy de impulso; dummy de nível; mudança exponencial e mudança racional. As duas últimas admitem a possibilidade de mudanças graduais ou não lineares. A primeira etapa do teste consiste na estimativa por mínimos quadrados generalizados dos parâmetros determinísticos da série, incluindo aqueles referentes à forma funcional da quebra (sendo esta determinada de forma endógena). Na segunda etapa, a presença de raiz unitária na série residual é verificada segundo o teste de Dickey-Fuller Aumentado. Assim, a hipótese nula do teste é de que a série é um caminho aleatório.
} 
Tabela 1: Resultados dos testes de raiz unitária

\begin{tabular}{|c|c|c|c|c|}
\hline \multicolumn{5}{|c|}{ Período considerado: agosto de 1999 a dezembro de 2012.} \\
\hline Série & Modelagem da quebra & Data da quebra & $\begin{array}{l}\text { Parâmetros determinísticos } \\
\text { e defasagens }\end{array}$ & Estatística teste \\
\hline \multirow{3}{*}{ Prod. Industrial } & Dummy de nível & \multirow{3}{*}{ Dez. de 2008} & Constante e Tendência; 1. & $-2,21$ \\
\hline & Mudança exponencial & & Constante e Tendência; 1. & $-2,2$ \\
\hline & Mudança racional & & Constante e Tendência; 0. & $-2,65$ \\
\hline$\triangle$ Prod. Industrial & Dummy de impulso & Dez. de 2008 & Constante; 0. & $-13,25^{* *}$ \\
\hline \multirow{2}{*}{ Inflação IPCA } & Dummy de impulso & \multirow{2}{*}{ Nov. de 2002} & Constante; 7. & $-3,40^{*}$ \\
\hline & Mudança racional & & Constante; 6. & $-3,57^{* *}$ \\
\hline \multirow{2}{*}{ Câmbio } & Mudança exponencial & \multirow{2}{*}{ Out. de 2002} & Constante e Tendência; 7. & $-1,18$ \\
\hline & Mudança racional & & Constante e Tendência; 7. & $-1,1$ \\
\hline \multirow{2}{*}{$\triangle$ Câmbio } & Dummy de impulso & \multirow{2}{*}{ Nov. de 2002} & Constante; 0. & $-7,48^{* *}$ \\
\hline & Mudança racional & & Constante; 0. & $-7,27^{* *}$ \\
\hline SELIC & Dummy de impulso & Jan. de 2003 & Constante e Tendência; 1 . & $-4,61^{* *}$ \\
\hline$\triangle$ SELIC & Dummy de impulso & Jan. de 2003 & Constante; 3. & $-5,01^{* *}$ \\
\hline
\end{tabular}

Elaboração dos autores.

Notas:

1) O número de defasagens utilizadas nos testes foi determinado com base nos critérios de Akaike, Schwarz, Hannan-Quinn e Erro de predição final. Quando houve divergências entre os critérios, optamos por:

i o número apontado pela maioria deles;

ii o maior número de defasagens.

2) * indica a rejeição da hipótese nula ao nível de significância de 5\%; ** indica a rejeição ao nível de $1 \%$.

Os resultados indicam ordens de integração distintas. ${ }^{6}$ As séries da inflação e da SELIC são estacionárias, sendo a estacionaridade desta última na tendência. Já a produção industrial e o câmbio são estacionárias em suas variações percentuais, sendo portanto integradas de ordem um. ${ }^{7}$

O passo seguinte para a especificação do modelo vetorial auto-regressivo (VAR) linear foi a determinação do seu número de defasagens. Para o caso dos modelos auto-regressivos univariados confrontados com modelos de transição suave, Teräsvirta (1994) e van Dijk et alii (2002) argumentam que tal escolha não deve se basear apenas nos critérios usuais de seleção, mas principalmente na questão da autocorrelação dos seus resíduos, pois a presença desta tende a viesar os resultados dos testes de linearidade, etapa imediatamente seguinte em nossa análise.

Seguindo o mesmo critério de determinação para o caso multivariado, e admitindo um máximo de até quatro defasagens para o mesmo, a ordem mais apropriada foi escolhida como sendo igual a três. Contudo, a opção por um modelo VAR (3) com as séries da inflação, SELIC e das variações percentuais da produção industrial e do câmbio nos levou ao ajuste de modelos não-lineares de transição suave cujas

\footnotetext{
${ }^{6}$ Caso os testes de raiz unitária indicassem que as séries são integradas de mesma ordem, seriam realizados testes de cointegração e estimar-se-ia um vetor de correção de erros não linear. Todavia, os resultados parecem evidenciar que a série da taxa Selic em nível é estacionária, enquanto as séries da taxa de câmbio e da produção industrial parecem ser integradas de ordem um I(1). Diante da evidência de que as séries não são integradas de mesma ordem, optou-se por estimar o modelo com a variação percentual da produção industrial, inflação, variação percentual da taxa de câmbio e variação da taxa Selic. Dessa forma, assim como em Weise (1999), todas as séries utilizadas nas estimações são estacionárias pelos testes de raiz unitária utilizados, ao nível de $1 \%$ de significância. Ressalta-se que as funções de resposta a impulso não lineares dos modelos estimados com as séries em nível (ou em logaritmo) foram instáveis, sendo que apenas os modelos com as séries estacionárias apresentaram respostas não explosivas.

${ }^{7}$ A fim de verificarmos a robustez dos resultados encontrados para a possível presença de duas quebras estruturais, optamos por também realizar o teste de raiz unitária proposto em Lee e Strazicich (2003) para cada uma das séries. Os resultados, porém, não diferiram qualitativamente daqueles apresentados na tabela 1.
} 
funções de resposta a impulso se mostraram instáveis. Tais funções passaram a apresentar um comportamento estável quando incorporamos no modelo vetorial não-linear a série da primeira diferença da SELIC no lugar da série em nível. A partir desta informação, foi especificado um modelo VAR linear com a primeira diferença da SELIC. ${ }^{8}$ O número de defasagens igual a um, num máximo de quatro, foi escolhido como o mais adequado.

\section{ESPECIFICAÇÃO DO MODELO DE TRANSIÇÃO SUAVE}

Nesta etapa, o modelo especificado na seção anterior será confrontado com um modelo vetorial autoregressivo de transição suave (que denominaremos de TSVAR) de mesma ordem, por meio da realização de alguns testes de hipótese quanto à linearidade. Estes testes permitem a seleção das variáveis de transição e da forma mais adequada da sua função.

Visando uma melhor compreensão, apresentaremos uma breve descrição formal do modelo e dos testes realizados, seguida dos resultados obtidos em nossa análise. Seja $\Delta Y_{t}$ o vetor contendo as séries de tempo da inflação e das variações da produção industrial, do câmbio e da SELIC no tempo $t$. O modelo TSVAR de ordem 1 pode ser representado da seguinte forma:

$$
\Delta Y_{t}=\left(\Phi_{1,0}+\Phi_{1,1} \Delta Y_{t-1}\right)+\left(\Phi_{2,0}+\Phi_{2,1} \Delta Y_{t-1}\right) G\left(s_{t} ; \gamma, c\right)+\varepsilon_{t}
$$

onde: $\Phi_{i, 0}, i=1,2$, são vetores $(4 \times 1)$ referentes aos parâmetros do intercepto, $\Phi_{i, 1}, i=1,2$, são matrizes $(4 \times 4)$ referentes aos parâmetros autoregressivos e $\varepsilon_{t}$ é um vetor $(4 \times 1)$ de ruídos brancos com média zero e matriz variância-covariância positiva definida $\Sigma$.

O termo $G\left(s_{t} ; \gamma, c\right)$ representa uma função contínua e limitada da variável de transição $s_{t}$, e pode ser interpretada como a função que define dois regimes distintos para o modelo em seus dois extremos. A variável de transição tanto pode ser exógena ao modelo como uma função das variáveis endógenas defasadas. O parâmetro $c$ é o threshold ou a fronteira entre os dois regimes, associados a valores de $s t$ acima ou abaixo de $c$. O parâmetro $\gamma$ determina a suavidade da transição entre os regimes. Quanto maior $\gamma$, mais rápida (ou menos suave) será transição a partir de $s_{t}=c$.

A dinâmica admitida para o modelo acima segue de perto os trabalhos de Weise (1999) e Rothman et alii (2001), no sentido que a mesma função de transição determinará os regimes e as mudanças entre eles em todas as equações do modelo.

Existem algumas possibilidades quanto à forma funcional de $G\left(s_{t} ; \gamma, c\right)$. Para cada uma delas, haverá uma interpretação peculiar sobre a dinâmica de $\Delta Y_{t}$. A forma mais apropriada para a caracterização de um comportamento assimétrico das variáveis nos diferentes regimes do modelo é a função logística de $1^{\text {a }}$ ordem, que pode ser representada pela seguinte expressão:

$$
G\left(s_{t} ; \gamma, c\right)=\frac{1}{1+\exp \left\{-\gamma\left(s_{t}+c\right)\right\}}-\frac{1}{2}, \gamma>0
$$

Neste caso, o modelo vetorial será denominado LTSVAR. De acordo com função acima, a dinâmica de $\Delta Y_{t}$ será distinta nas situações em que $s_{t}>c$ e $s_{t}<c$. Ademais, quando o parâmetro $\gamma$ for muito grande, a função tenderá a 0,5 e a mudança de regime a partir de $s_{t}=c$ será quase instantânea, tendendo a um modelo de threshold. Por outro lado, a equação (1) se reduzirá a um modelo VAR linear quando $\gamma=0$.

A alternativa mais comum à dinâmica assimétrica caracterizada pela função logística é a função exponencial, dada pela seguinte expressão:

$$
G\left(s_{t} ; \gamma, c\right)=1+\exp \left\{-\gamma\left(s_{t}+c\right)^{2}\right\}, \gamma>0
$$

\footnotetext{
${ }^{8}$ Uma justificativa adicional para a utilização da primeira diferença da SELIC no lugar da série em nível é que esta última é estacionária na tendência. Assim, tal opção evitaria a necessidade de incluirmos o parâmetro determinístico da tendência nos modelos estimados.
} 
Esta função é simétrica em relação ao parâmetro $c$, indicando que a dinâmica de $\Delta Y_{t}$ será idêntica nas situações em que a diferença entre os valores de $s_{t}$ e $c$ tiver o mesmo valor absoluto. Neste caso, o modelo vetorial será denominado ETSVAR. ${ }^{9}$

O teste de linearidade é a etapa inicial na construção de um modelo de transição suave. Segundo Teräsvirta (2004), o teste tem como propósito verificar a linearidade em relação a diferentes possibilidades no espaço dos parâmetros, selecionando o modelo e a variável de transição mais adequados.

No caso do modelo descrito por (1), as hipóteses nula e alternativa do teste de linearidade podem ser expressas como: $H_{0}: \Phi_{2, j}=0$, para $j=0,1$, contra $H_{1}: \Phi_{2, j} \neq 0$, para ao menos um $j \in\{0,1\}$. Ou alternativamente, como: $H_{0}^{\prime}: \gamma=0$ contra $H_{1}^{\prime}: \gamma>0$.

Assim como em outros casos de modelos não lineares, o teste é complicado pela presença de alguns parâmetros que não estão identificados sob $H_{0}$. Ou seja, parâmetros que não estariam restritos sob tal hipótese, mas nada pode ser assimilado sobre eles quando esta for válida. Assim, sob $H_{0}: \Phi_{2, j}=0$, os parâmetros $\gamma$ e $c$ da função de transição não estarão identificados. Analogamente, se $H_{0}: \gamma=0$ for válida, as matrizes $\Phi_{2, j}$ e o parâmetro $c$ não estarão identificados. A principal consequência desta ausência de identificação é que as estatísticas-teste consideradas tenderão a distribuições assintóticas não padronizadas sob $H_{0}$, fazendo com que suas expressões analíticas não estejam disponíveis com frequência, e implicando que os valores críticos dos testes tenham que ser obtidos por meio de simulação.

No contexto dos modelos autoregressivos de transição suave, Luukkonen et alii (1988) buscaram contornar o problema da identificação pela aproximação da função de transição por expansões de Taylor de segunda e terceira ordens ao redor de $\gamma=0$. Nesse caso, as estatísticas-teste decorrentes tendem, mediante certas condições, à distribuição qui-quadrado $\left(\chi^{2}\right)$.

Iniciaremos nossa análise sobre a linearidade buscando a aplicação, em cada uma das equações do modelo vetorial, de um procedimento similar ao proposto em Luukkonen et alii (1988). ${ }^{10}$ Considerando o caso geral de um modelo vetorial de ordem $p$ e com $k$ variáveis, seja $w_{t}=\left(\Delta y_{1 t-1}, \ldots, \Delta y_{1 t-p}, \ldots\right.$, $\left.\Delta y_{k t-1}, \ldots, \Delta y_{k t-p}\right)$ o conjunto de todas as suas variáveis endógenas defasadas. Assumindo que a função de transição é logística de $1^{a}$ ordem e que a variável $s_{t}$ é conhecida, a aplicação do teste de linearidade convencional à $i$-ésima equação do modelo vetorial envolve os seguintes passos:

i) Estimativa por mínimos quadrados ordinários (MQO) da seguinte regressão:

$$
\Delta y_{i t}=\varphi_{i 0}+\sum_{j=1}^{p k} \varphi_{i j} w_{t}+\varepsilon_{i t},(i \text {-ésima equação do modelo VAR }) \text {. }
$$

Cálculo de $S Q R_{0}=\sum_{t=1}^{T} \hat{\varepsilon}_{i t}^{2}$, onde $T$ é o número de observações.

ii) Estimativa por MQO da seguinte regressão auxiliar:

$$
\Delta y_{i t}=\beta_{i 0}+\sum_{j=1}^{p k} \beta_{i j} w_{t}+\sum_{j=1}^{p k} \delta_{1 j} w_{t} s_{t}+\sum_{j=1}^{p k} \delta_{2 j} w_{t} s_{t}^{2}+\sum_{j=1}^{p k} \delta_{3 j} w_{t} s_{t}^{3}+v_{i t} .
$$

Cálculo de $S Q R_{1}=\sum_{t=1}^{T} \hat{v}_{i t}^{2}$.

\footnotetext{
${ }^{9}$ Outra forma alternativa é a função logística de $2^{a}$ ordem, com dois parâmetros de threshold $\left(c_{1}\right.$ e $c_{2}$, sendo que $c_{1} \leq c_{2}$ ). Esta é a forma mais apropriada quando a dinâmica de $Y_{t}$ for similar para $s_{t}<c_{1}$ e $s_{t}>c_{2}$, e distinta quando $c_{1}<s_{t}<c_{2}$. Essa função é simétrica em relação a $\frac{c_{1}+c_{2}}{2}$. Para detalhes, veja van Dijk et alii (2002) e Teräsvirta (2004).

${ }^{10}$ Uma vantagem adicional desse procedimento é que o modelo sob a hipótese alternativa não precisa ser estimado.
} 
iii) Sob a hipótese $H_{0}: \delta_{1 j}=\delta_{2 j}=\delta_{3 j}=0$ (o que equivale a $H_{0}: \gamma=0$ ), e admitindo que os erros da regressão estimada no passo $i$ ) são normalmente distribuídos e satisfazem determinadas condições de momento, a estatística-teste $L M_{3}=\frac{T\left(S Q R_{0}-S Q R_{1}\right)}{S Q R_{0}}$ tem distribuição assintótica $\chi_{(3 p k)}^{2}$. Para o caso de amostras pequenas, recomenda-se o uso da versão $F$ dessa estatística, que é dada por $L M_{3}=\frac{\left(S Q R_{0}-S Q R_{1}\right) /(3 p k)}{S Q R_{0} /(T-4 p k-1)}$, com distribuição aproximada $F_{(3 p k, T-4 p k-1)} \cdot{ }^{11}$

Caso ocorra a rejeição da linearidade, a etapa seguinte será a seleção da forma mais apropriada para a função de transição. Segundo van Dijk et alii (2002), na prática, esta escolha ocorre com base em uma sequência de hipóteses nulas sobre os parâmetros $\delta_{1 j}, \delta_{2 j}$ e $\delta_{3 j}$ da regressão auxiliar do passo $i i$ ), limitando-se entre a função logística de $1^{a}$ ordem e as funções exponencial ou logística de $2^{a}$ ordem. Formalmente, na estimativa da regressão auxiliar referente à $i$-ésima equação do modelo vetorial, é testada a seguinte sequência de hipóteses nulas:

i) $H_{03}: \delta_{3 j}=0$;

ii) $H_{02}: \delta_{2 j}=0 \mid \delta_{3 j}=0$;

iii) $H_{01}: \delta_{1 j}=0 \mid \delta_{3 j}=\delta_{2 j}=0$;

Como, em cada uma das equações do modelo, os parâmetros $\delta_{1 j}, \delta_{2 j}$ e $\delta_{3 j}$ são expressos em termos dos parâmetros originais, é possivel estabelecer as seguintes relações:

i) $\delta_{3 j} \neq 0$ apenas se a função mais apropriada for logística de $1^{a}$ ordem;

ii) $\delta_{2 j}=0$ se a função mais apropriada for logística de $1^{a}$ ordem com os parâmetros do intercepto iguais nos dois regimes $\left(\varphi_{1,0}=\varphi_{2,0}\right)$ e $c=0$, mas $\delta_{2 j} \neq 0$ sempre que a função mais apropriada for exponencial;

iii) $\delta_{1 j}=0$ se a função mais apropriada for exponencial com os parâmetros do intercepto iguais nos dois regimes $\left(\varphi_{1,0}=\varphi_{2,0}\right)$ e $c=0$, mas $\delta_{1 j} \neq 0$ sempre que a função mais apropriada for logística de $1^{a}$ ordem.

Portanto, a combinação das três propriedades acima leva à seguinte regra de decisão: se o $p$-valor do teste correspondente à hipótese $H_{02}$ for o menor na sequência de hipóteses testadas, a função exponencial deverá ser selecionada; nos outros casos, a função logística de $1^{a}$ ordem deve ser preferida.

Como observado na descrição do teste de linearidade, a variável de transição deve ser conhecida a priori. No contexto da análise dos efeitos assimétricos de choques monetários, Weise (1999) sugere que a cada hipótese teórica é possível associar a escolha de uma ou mais variáveis de transição. Por exemplo, no caso da assimetria resultante do acelerador financeiro, a variável poderia ser o produto, a política monetária ou mesmo um indicador de crédito, como em Balke (2000). Ademais, uma relação não linear entre duas variáveis pode implicar que uma terceira também tenha comportamento assimétrico, podendo ser igualmente aceita como variável de transição. ${ }^{12}$ Ademais, se uma teoria prevê mais de uma

\footnotetext{
${ }^{11}$ A estatística $L M_{3}$ foi desenvolvida para o teste em que a hipótese alternativa é um modelo de transição suave com função logística de $1^{a}$ ordem. Contudo, o teste também tem poder para o caso em que a alternativa é um modelo com função exponencial. Ver van Dijk et alii (2002) para maiores detalhes.

${ }^{12}$ Exemplificando, tomem-se as variáveis inflação e crescimento do produto, relacionadas por uma Curva de Phillips. Schaling (2004) mostra que, em economias sob o regime de metas para a inflação, se a Curva de Phillips for não-linear a taxa de juros ótima também responderá de forma não-linear ao hiato de produto e ao desvio da inflação em relação à meta. A convexidade da Curva de Phillips implica que um mesmo desvio positivo do produto em relação a seu potencial é mais inflacionário em fases expansivas que em fases recessivas da economia. Isso implica em uma resposta assimétrica do Banco Central para corrigir desvios da inflação esperada em relação à meta de inflação: dado o desvio, o aumento de juros será mais intenso na fase expansiva do ciclo econômico.
} 
possível variável de transição, o procedimento de verificar se os resultados do modelo permanecem os mesmos com a troca da variável nesse papel equivale a um teste de robustez da validade empírica da teoria. Tomando como exemplo o caso da validade da curva de oferta agregada convexa, tanto o produto quanto os preços deveriam ser variáveis de transição adequadas.

Optamos, assim, por testar as quatro variáveis do modelo quanto à linearidade. Contudo, ao invés de considerarmos as mesmas defasadas em um ou mais períodos (procedimento mais usual, uma vez que são variáveis endógenas), optamos por analisar suas variações no período de doze meses. A justificativa para isso é que buscaremos caracterizar regimes relacionados a mudanças mais persistentes na variável de transição, que estariam relacionadas ao ciclo de negócios, à persistência da inflação ou à política monetária. Nesse sentido, as variações percentuais da produção industrial e do câmbio, a inflação e a variação da SELIC se mostram mais adequadas se analisadas em intervalos de doze meses. ${ }^{13}$

Na tabela 2 são apresentados os resultados dos testes para cada uma das variáveis candidatas, defasadas em até quatro períodos. Devido às características das séries, o teste utilizado é uma ligeira modificação do caso convencional acima descrito, sendo robusto à presença de outliers. ${ }^{14}$ As estatísticasteste $L M_{3}$ (versão F) são referentes a cada uma das equações do modelo. O valor- $p$ associado está reportado entre parênteses.

Tabela 2: Resultados dos testes de linearidade.

Período considerado: dezembro de 2000 a dezembro de 2012.

Estatísticas LM3 (versão F) - por equação do modelo.

Valor- $p$ entre parênteses.

Variáveis de transição:

Variáveis dependentes em cada equação:

\begin{tabular}{|c|c|c|c|c|}
\hline & \multicolumn{4}{|c|}{. } \\
\hline & $\triangle$ Produção Industrialt & Inflaçãot & $\triangle$ Câmbiot & $\triangle$ SELICt \\
\hline \multirow{2}{*}{$\triangle 12$ Prod. Ind.t-1 } & 1,61 & 0,81 & 0,58 & 3,02 \\
\hline & $(0,08)$ & $(0,67)$ & $(0,88)$ & $(0,00)$ \\
\hline \multirow{2}{*}{$\triangle 12$ Prod. Ind.t-2 } & 1,86 & 1,27 & 1,25 & 3,01 \\
\hline & $(0,03)$ & $(0,23)$ & $(0,24)$ & $(0,00)$ \\
\hline \multirow{2}{*}{$\triangle 12$ Prod. Ind.t-3 } & 1,43 & 1,28 & 1 & 2,14 \\
\hline & $(0,14)$ & $(0,22)$ & $(0,46)$ & $(0,01)$ \\
\hline \multirow{2}{*}{$\triangle 12$ Prod. Ind.t-4 } & 1,08 & 0,73 & 1,88 & 1,83 \\
\hline & $(0,38)$ & $(0,74)$ & $(0,03)$ & $(0,04)$ \\
\hline
\end{tabular}

\footnotetext{
${ }^{13}$ Rothman et alii (2001) argumentam que variações mensais não são adequadas como variáveis de transição porque carregam flutuações de curto-prazo que não representam necessariamente mudanças de regime.

${ }^{14}$ Os resultados do teste de linearidade convencional são sensíveis à presença de autocorrelação, heteroscedasticidade e outliers nos resíduos dos modelos considerados, levando à rejeição espúria da hipótese nula frequentemente. O teste robusto à presença de outliers nas séries está descrito em van Dijk et alii (2002). A diferença básica em relação ao teste convencional é a estimativa por mínimos quadrados ponderados, que atribui pesos menores para as observações admitidas como outliers.
} 


\begin{tabular}{|c|c|c|c|c|}
\hline \multirow{2}{*}{ Inflação(12M)t-1 } & 2,04 & 1,05 & 1,02 & 1,32 \\
\hline & $(0,02)$ & $(0,41)$ & $(0,43)$ & $(0,20)$ \\
\hline \multirow{2}{*}{ Inflação(12M)t-2 } & 1,47 & 0,92 & 1,24 & 1,66 \\
\hline & $(0,13)$ & $(0,54)$ & $(0,25)$ & $(0,07)$ \\
\hline \multirow{2}{*}{ Inflação(12M)t-3 } & 1,65 & 1,06 & 1,28 & 2,04 \\
\hline & $(0,07)$ & $(0,40)$ & $(0,22)$ & $(0,02)$ \\
\hline \multirow{2}{*}{ Inflação(12M)t-4 } & 2,01 & 1,24 & 1,26 & 2,26 \\
\hline & $(0,02)$ & $(0,25)$ & $(0,23)$ & $(0,01)$ \\
\hline \multirow{2}{*}{$\triangle 12$ Câmbiot-1 } & 1,58 & 0,45 & 2,93 & 1,02 \\
\hline & $(0,09)$ & $(0,96)$ & $(0,00)$ & $(0,43)$ \\
\hline \multirow{2}{*}{$\triangle 12$ Câmbio t-2 } & 1,75 & 0,69 & 3,51 & 1,25 \\
\hline & $(0,05)$ & $(0,79)$ & $(0,00)$ & $(0,25)$ \\
\hline \multirow{2}{*}{$\triangle 12$ Câmbio t-3 } & 1,88 & 0,98 & 1,91 & 1,5 \\
\hline & $(0,03)$ & $(0,48)$ & $(0,03)$ & $(0,11)$ \\
\hline \multirow{2}{*}{$\triangle 12$ Câmbio t-4 } & 2,57 & 0,8 & 1,71 & 0,68 \\
\hline & $(0,00)$ & $(0,68)$ & $(0,06)$ & $(0,80)$ \\
\hline \multirow{2}{*}{$\triangle 12$ SELICt-1 } & 1,51 & 0,74 & 0,91 & 2,6 \\
\hline & $(0,11)$ & $(0,74)$ & $(0,55)$ & $(0,00)$ \\
\hline \multirow{2}{*}{$\triangle 12$ SELICt-2 } & 1,47 & 0,75 & 0,95 & 2,18 \\
\hline & $(0,12)$ & $(0,74)$ & $(0,51)$ & $(0,01)$ \\
\hline \multirow{2}{*}{$\triangle 12$ SELICt-3 } & 1,48 & 0,91 & 0,91 & 2,05 \\
\hline & $(0,12)$ & $(0,56)$ & $(0,56)$ & $(0,02)$ \\
\hline \multirow{2}{*}{$\triangle 12$ SELICt-4 } & 1,27 & 1 & 0,79 & 1,67 \\
\hline & $(0,23)$ & $(0,46)$ & $(0,69)$ & $(0,06)$ \\
\hline
\end{tabular}

Elaboração dos autores.

Notas:

1) A hipótese nula (H0) do teste afirma que a equação estimada é linear. A hipótese alternativa é em favor de uma equação de transição suave.

2) 0 operador $\Delta 12$ denota a variação em 12 períodos. Ou seja, $\Delta 12 y t=y t-y t-12$. A inflação como variável de transição também foi considerada em um período de doze meses.

No contexto das equações que compõem o modelo, e considerando os níveis usuais de significância de 1,5 e $10 \%$, os resultados apontam que a hipótese nula foi rejeitada com maior frequência nas equações referentes às variações da taxa SELIC e da produção industrial, sugerindo que estas se comportaram de maneira não linear em relação às condições determinadas pela produção e inflação anuais passadas. Há também evidências de não linearidade nas equações da produção industrial, em relação ao câmbio, e da SELIC em relação às suas variações anuais defasadas. Por outro lado, há poucas evidências quanto à não-linearidade do câmbio (apenas quanto às suas próprias variações passadas) e nenhuma com relação à inflação. 
Em vista dos resultados obtidos, as variáveis referentes à inflação e às variações da produção anuais podem ser admitidas como candidatas à transição para o conjunto do modelo vetorial. Para a escolha das defasagens mais adequadas, seguimos o critério proposto em Teräsvirta (1994) para o caso dos modelos de equação única, onde a determinação é feita com base no menor valor- $p$ obtido nos testes de linearidade. ${ }^{15}$ Assim, definimos como candidatas para variável de transição a variação anual da produção industrial com defasagem de dois meses e a inflação anual defasada em quatro períodos.

As duas variáveis escolhidas foram então consideradas na etapa de seleção da forma mais apropriada para a função de transição. Para cada uma delas, foi testada a sequência de hipóteses nulas $H_{03}, H_{02}$ e $H_{01}$ nas quatro equações do modelo vetorial. A tabela 3 apresenta os resultados do teste robusto à presença de outliers, sendo reportados apenas os valores p das estatísticas-teste correspondentes a cada uma das hipóteses.

Tabela 3: Resultados dos testes de seleção da função de transição.

\begin{tabular}{|c|c|c|c|c|}
\hline \multicolumn{5}{|c|}{ Período considerado: dezembro de 2000 a dezembro de 2012 . } \\
\hline \multirow[b]{2}{*}{ Variáveis de transição: } & \multicolumn{4}{|c|}{$\begin{array}{l}\text { Valores-p correspondentes ao teste LM (versão F) - por equação do modelo. } \\
\text { Variáveis dependentes em cada equação: }\end{array}$} \\
\hline & $\Delta$ Produção Industrialt & Inflaçãot & $\Delta$ Câmbiot & $\Delta$ SELIC $t$ \\
\hline \multirow[t]{2}{*}{$\Delta 12$ Prod. Ind.t -2} & $\begin{array}{l}\text { H03: } 0,016 \\
\text { H02: } 0,224 \\
\text { H01: } 0,511\end{array}$ & $\begin{array}{l}\text { H03: } 0,391 \\
\text { H02: } 0,182 \\
\text { H01: } 0,205\end{array}$ & $\begin{array}{l}\text { H03: } 0,572 \\
\text { H02: } 0,691 \\
\text { H01: } 0,071\end{array}$ & $\begin{array}{l}\text { H03: } 0,176 \\
\text { H02: } 0,023 \\
\text { H01: } 0,013\end{array}$ \\
\hline & $\begin{array}{l}\text { Evidência favorável } \\
\text { à função logística } \\
\text { de } 1^{\text {a }} \text { ordem. }\end{array}$ & & $\begin{array}{l}\text { Evidência favorável } \\
\text { à função logística } \\
\text { de } 1^{\mathrm{a}} \text { ordem. }\end{array}$ & $\begin{array}{l}\text { Evidência favorável } \\
\text { à função logística } \\
\text { de } 1^{\mathrm{a}} \text { ordem. }\end{array}$ \\
\hline Inflação(12M) $t-4$ & $\begin{array}{l}\text { H03: } 0,739 \\
\text { H02: } 0,335 \\
\text { H01: } 0,022 \\
\text { Evidência favorável } \\
\text { à função logística } \\
\text { de } 1^{\mathrm{a}} \text { ordem. }\end{array}$ & $\begin{array}{l}\text { H03: } 0,602 \\
\text { H02: } 0,719 \\
\text { H01: } 0,044 \\
\text { Evidência favorável } \\
\text { à função logística } \\
\text { de } 1^{\text {a }} \text { ordem. }\end{array}$ & $\begin{array}{l}\text { H03: } 0,222 \\
\text { H02: } 0,154 \\
\text { H01: } 0,446\end{array}$ & $\begin{array}{l}\text { H03: } 0,001 \\
\text { H02: } 0,136 \\
\text { H01: } 0,002 \\
\text { Evidência favorável } \\
\text { à função logística } \\
\text { de } 1^{\text {a }} \text { ordem. }\end{array}$ \\
\hline
\end{tabular}

Elaboração dos autores.

Notas:

i) Os valores- $p$ estão associados às estatísticas $\mathrm{F}$ correspondentes às hipóteses $\mathrm{H} 03, \mathrm{H} 02 \mathrm{ou} H 01$.

\footnotetext{
${ }^{15} \mathrm{~A}$ rationale deste procedimento é que o teste de linearidade deveria ter máximo poder no caso em que o modelo sob a hipótese alternativa está corretamente especificado, ou seja, com a variável de transição adequada. Resultados de simulações em Teräsvirta (1994) corroboram este critério.
} 
Considerando os níveis usuais de significância, os resultados obtidos apontam o predomínio da função logística de $1^{a}$ ordem, sendo esta a mais adequada em todas as equações. Assim, todas as variáveis do modelo podem ser caracterizadas por um comportamento assimétrico quando a inflação e a variação da produção industrial em doze meses são consideradas como responsáveis pela transição.

\section{RESULTADOS QUANTO ÀS ESTIMATIVAS DOS PARÂMETROS}

Após a seleção das variáveis de transição candidatas e da forma funcional, a etapa seguinte consiste na estimativa do conjunto de parâmetros $\left(\Phi_{1,0}, \Phi_{2,0}, \Phi_{1,1}, \Phi_{2,1}, \gamma, c\right)$ do modelo de transição suave, o que envolve a resolução de um problema de otimização não linear em relação aos parâmetros autoregressivos e do intercepto. Na prática, faz-se uso do fato que, para valores fixos e conhecidos de $\gamma$ e $c$, o modelo se torna linear nos demais parâmetros e a estimativa dos mesmos pode ser obtida condicionalmente àqueles valores. Assim, o problema original tem sua dimensão reduzida, sendo primeiramente resolvido apenas em relação aos parâmetros $\gamma$ e $c .^{16}$

A partir desta linearidade condicional, uma forma conveniente de se obter valores iniciais de $\gamma$ e $c$ sensíveis ao algoritmo de otimização é por um procedimento de grid search bidimensional. Inicialmente, fixando os valores dos parâmetros da função de transição, os demais podem ser estimados por mínimos quadrados ordinários, computando-se a soma dos quadrados dos resíduos. Este processo é repetido para diversas combinações de valores de $\gamma$ e $c$, selecionando aquela que minimizar a referida soma dos quadrados.

Em vista de algumas limitações que nos deparamos com relação à estimativa de $\gamma \mathrm{e} c$ e à avaliação da especificação no contexto do modelo vetorial, ${ }^{17}$ optamos por encontrar estimativas adequadas a partir de cada uma das equações. Assim, iniciamos pela construção dos grids de valores iniciais possíveis para $\gamma$ e $c$ em cada equação e para cada variável de transição candidata. No caso do grid para o threshold, seguimos a recomendação de van Dijk et alii (2002), dividindo o conjunto de valores amostrais de cada uma das variáveis candidatas em decis e excluindo o primeiro e o último para evitar valores extremos. Os valores restantes, do segundo ao nono decis, foram divididos em cinco intervalos de mesma amplitude. Quanto ao parâmetro da velocidade de transição, o mais usual é torná-lo livre de escala, facilitando a construção do grid efetivo. Isso é realizado através de um pequeno ajuste na função (logística de $1^{a}$ ordem), tal que $G\left(s_{t} ; \gamma, c\right)=\left(1+\exp \left\{-\gamma\left(s_{t}+c\right)^{2}\right\} / \sigma_{s}\right)^{-1}$, onde $\sigma_{s}$ representa o desvio-padrão amostral da variável de transição. Como valores iniciais possíveis para $\gamma$, definimos aqueles situados na faixa de 1 a 50, com intervalos de 1 em 1 para $\gamma=1, \ldots, 10$, e de 5 em 5 para $\gamma=10, \ldots, 50$. A aplicação do procedimento de grid search em cada equação envolveu a combinação de todos os intervalos de valores considerados para $\gamma$ e $c$.

Uma vez encontrados os valores iniciais para os dois parâmetros da função de transição, cada equação do modelo foi estimada por máxima verossimilhança pela aplicação do algoritmo iterativo BFGS ${ }^{18}$. As estimativas foram então avaliadas em relação à magnitude dos valores numéricos finais obtidos para $\gamma$ e $c$, como também em função dos resultados dos testes diagnósticos quanto à presença de autocorrelação e efeito ARCH nos resíduos; e dos testes referentes à não-linearidade restante e constância paramétrica da equação estimada. ${ }^{19}$

\footnotetext{
${ }^{16}$ Ver van Dijk et alii (2002) para maiores detalhes sobre a estimação dos parâmetros nos modelos de transição suave.

${ }^{17}$ As limitações se referem às dificuldades computacionais de se obter estimativas de $\gamma$ e $c$ e de avaliação (testes de especificação) no contexto dos modelos multivariados simultâneos de transição suave.

${ }^{18} \mathrm{~A}$ sigla refere-se ao algoritmo de Broyden, Fletcher, Goldfarb e Shanno, destinado à resolução de problemas de otimização não linear. Para maiores detalhes, ver, por exemplo, (Hendry (1995), Apêndice A5).

${ }^{19}$ Os testes de especificação referentes às hipóteses de ausência de autocorrelação, não-linearidade aditiva e constância paramétrica são característicos dos modelos de transição suave univariados e foram inicialmente desenvolvidos em Eitrheim e Teräsvirta (1996).
} 
De modo geral, para as duas variáveis de transição candidatas, foram encontrados valores elevados (muito acima de 100 na maioria dos casos) para as estimativas finais do parâmetro $\gamma$ em todas as equações, além da identificação de alguns problemas pelos testes de diagnóstico dos resíduos. ${ }^{20}$ Assim, em vista das evidências de rápidas transições entre os regimes em cada equação, optamos por fixar o valor de $\gamma$ como sendo igual a 100 para as duas variáveis de transição. Uma justificativa para esta suposição está no fato de que grandes mudanças na magnitude da velocidade acarretam pequenas variações nos valores da função de transição (van Dijk et alii, 2002), não sendo, pois, necessária uma estimativa altamente acurada para $\gamma$. Em seguida, os valores de c para cada variável de transição (e, consequentemente, os demais parâmetros dos modelos, cujas estimativas são condicionadas aos valores obtidos de $\gamma$ e $c$ ) foram determinados com base nos seguintes critérios para o modelo estimado:

i) funções de resposta a impulso estáveis ${ }^{21}$ e livres do problema do price puzzle; ${ }^{22}$

ii) potencial de previsão;

iii) valores de $c$ que permitam um número razoável de observações para os dois regimes. A partir destes critérios, foi selecionado o valor $c_{1}=1,5$ para a variável de transição referente à variação em doze meses da produção industrial defasada em dois períodos (que, junto com $\gamma_{1}=100$, caracteriza a função de transição do modelo 1); e o valor $c_{2}=5,04$ para a inflação em doze meses defasada em quatro períodos (modelo 2).

A tabela 4 apresenta os resultados das estimativas dos modelos vetoriais com as duas variáveis de transição (para os valores acima selecionados dos parâmetros $\gamma$ e $c$ ). Nos dois casos, foi testada a significância conjunta dos coeficientes relativos à parte não linear (regime 2) em cada equação e no modelo como um todo. Nos dois modelos, há evidências estatísticas quanto à não-linearidade dos parâmetros, embora estas sejam mais fortes no caso do modelo 1. Os resultados sugerem que a não linearidade está presente nas equações da variação da SELIC e, em menor grau, na inflação.

Os modelos estimados serão utilizados para avaliar as respostas da produção industrial e da inflação aos choques monetários. Estas serão apresentadas em detalhes na próxima seção.

O potencial dos modelos estimados em previsões fora da amostra foi verificado em uma comparação com o VAR linear especificado na seção 3. Os modelos foram estimados utilizando-se as observações até dezembro de 2010. Realizou-se, então, previsões para horizontes temporais de 6, 12, 18 e 24 meses, computando-se os erros quadráticos médios (EQM) e os erros acumulados para os modelos não lineares e linear. As tabelas A.2 e A.3 do Apêndice apresentam os resultados. Os modelos 1 e 2 tiveram desempenho inferior ao modelo linear nas previsões para o crescimento da produção industrial, sendo o desempenho do modelo 1 ligeiramente inferior. No caso das previsões para a inflação, os modelos não lineares tiveram desempenho superior, com vantagem para o modelo 2.

\footnotetext{
${ }^{20}$ Detalhes dos resultados desta etapa foram omitidos por questão de limitação de espaço, mas podem ser obtidos mediante solicitação aos autores.

${ }^{21}$ Em modelos lineares, isso é facilmente verificado pela análise do módulo das raízes características. Já em um modelo de transição suave, aquelas raízes dependem do valor assumido pela função de transição $G(\cdot)$. Considerando que $G(\cdot)$ depende tanto da variável de transição como do estado do sistema (obtido através de simulação) e que as variáveis candidatas são determinadas endogenamente nos modelos, é difícil determinar o valor de $G(\cdot)$ e, por conseguinte, conhecer as raízes características do modelo LTSVAR. Assim, o critério para avaliar a estabilidade dos modelos foi gerar funções de resposta a impulso para 240 períodos e verificar se estas são convergentes ou têm trajetórias explosivas.

${ }^{22}$ Chama-se price puzzle a ocorrência de sinais invertidos aos que teoria prevê na resposta dos preços aos choques monetários: contrações monetárias elevando preços e expansões monetárias reduzindo preços. Para maiores detalhes sobre esse tópico, ver Sims (1992).
} 
Tabela 4: Resultados das estimativas dos modelos vetoriais de transição suave. Estatísticas- $t$ entre parênteses.

\begin{tabular}{|c|c|c|c|c|c|c|c|c|}
\hline \multirow[t]{2}{*}{ Coeficientes: } & \multicolumn{4}{|c|}{$\begin{array}{l}\text { Variável de transição: } \Delta 12 \text { Prod. Ind. } t-2 . \\
\text { Parâmetros da função de transição: } \\
\mathrm{c}=1,5 \text { e gamma }=100 \text {. } \\
\text { Período: julho de } 2001 \text { a dezembro de } 2012 \text {. }\end{array}$} & \multicolumn{4}{|c|}{$\begin{array}{l}\text { Variável de transição: Inflação( } 12 \mathrm{~m}) t-4 \text {. } \\
\text { Parâmetros da função de transição: } \\
c=5,04 \text { e gamma }=100 \text {. } \\
\text { Período: setembro de } 2001 \text { a dezembro de } 2012 \text {. }\end{array}$} \\
\hline & $\begin{array}{c}\Delta \text { Prod. } \\
\text { Industrialt }\end{array}$ & Inflaçãot & $\Delta$ Câmbiot & $\Delta$ SELICt & $\begin{array}{c}\Delta \text { Prod. } \\
\text { Industrialt }\end{array}$ & Inflaçãot & $\Delta$ Câmbiot & $\Delta$ SELICt \\
\hline \multirow{2}{*}{$\begin{array}{l}\text { Intercepto } \\
\text { (Regime 1) }\end{array}$} & 0,07 & 0,33 & 1,96 & $-0,27$ & 0,25 & 0,09 & $-1,44$ & $-0,13$ \\
\hline & $(0,11)$ & $(5,29)$ & $(1,65)$ & $(-2,14)$ & $(0,38)$ & $(0,90)$ & $(-1,41)$ & $(-2,32)$ \\
\hline \multirow{2}{*}{$\begin{array}{l}\text { Intercepto } \\
\text { (Regime 2) }\end{array}$} & 0,46 & $-0,13$ & $-1,58$ & 0,23 & $-0,07$ & 0,13 & 2,59 & 0,01 \\
\hline & $(0,67)$ & $(-1,56)$ & $(-1,12)$ & $(1,74)$ & $(-0,08)$ & $(1,18)$ & $(1,82)$ & $(0,13)$ \\
\hline \multirow{2}{*}{$\begin{array}{l}\Delta \text { Prod. Ind. } t-1 \\
\text { (Regime 1) }\end{array}$} & 0,19 & 0,01 & 0,31 & 0 & $-0,33$ & $-0,03$ & $-0,31$ & $-0,04$ \\
\hline & $(0,50)$ & $(0,83)$ & $(1,16)$ & $(0,36)$ & $(-1,63)$ & $(-2,04)$ & $(-1,20)$ & $(-2,17)$ \\
\hline \multirow{2}{*}{$\begin{array}{l}\text { Prod. Ind.t }-1 \\
\text { (Regime 2) }\end{array}$} & $-0,4$ & 0,02 & $-0,62$ & $-0,03$ & 0,42 & 0,06 & 0,3 & 0,03 \\
\hline & $(-0,97)$ & $(0,53)$ & $(-1,50)$ & $(-1,33)$ & $(1,31)$ & $(2,20)$ & $(0,75)$ & $(1,54)$ \\
\hline \multirow{2}{*}{$\begin{array}{l}\text { Inflaçãot }-1 \\
\text { (Regime 1) }\end{array}$} & $-0,05$ & 0,29 & $-3,37$ & 0,18 & 0,75 & 0,76 & 1,24 & 0,37 \\
\hline & $(-0,07)$ & $(2,63)$ & $(-1,47)$ & $(0,88)$ & $(0,53)$ & $(4,62)$ & $(0,62)$ & $(2,93)$ \\
\hline \multirow{2}{*}{$\begin{array}{l}\text { Inflaçãot }-1 \\
\text { (Regime 2) }\end{array}$} & $-0,43$ & 0,31 & 3,23 & 0,01 & $-0,8$ & $-0,15$ & $-2,62$ & $-0,23$ \\
\hline & $(-0,48)$ & $(1,96)$ & $(1,22)$ & $(0,04)$ & $(-0,52)$ & $(-0,80)$ & $(-1,03)$ & $(-1,17)$ \\
\hline \multirow{2}{*}{$\begin{array}{l}\Delta \text { Câmbiot }-1 \\
\text { (Regime 1) }\end{array}$} & $-0,07$ & 0,02 & 0,55 & 0 & $-0,05$ & $-0,03$ & $-0,05$ & $-0,02$ \\
\hline & $(-1,42)$ & $(1,73)$ & $(4,90)$ & $(-0,16)$ & $(-0,36)$ & $(-2,06)$ & $(-0,25)$ & $(-1,94)$ \\
\hline \multirow{2}{*}{$\begin{array}{l}\Delta \text { Cambio } t-1 \\
\text { (Regime 2) }\end{array}$} & $-0,04$ & 0 & $-0,18$ & 0,02 & $-0,05$ & 0,06 & 0,45 & 0,03 \\
\hline & $(-0,33)$ & $\begin{array}{l}(0,18) \\
\end{array}$ & $(-0,84)$ & $(0,93)$ & $(-0,36)$ & $(2,92)$ & $(1,80)$ & $(2,20)$ \\
\hline \multirow{2}{*}{$\begin{array}{l}\Delta \text { SELIC } t-1 \\
\text { (Regime 1) }\end{array}$} & $-0,84$ & 0,03 & 1,66 & 0,74 & $-0,67$ & $-0,12$ & $-0,67$ & 0,79 \\
\hline & $(-1,47)$ & $(0,47)$ & $(1,67)$ & $(4,68)$ & $(-0,81)$ & $(-0,89)$ & $(-0,55)$ & $(7,41)$ \\
\hline \multirow{2}{*}{$\begin{array}{l}\Delta \text { SELIC } t-1 \\
\text { (Regime 2) }\end{array}$} & 0,52 & 0,16 & $-1,97$ & $-0,09$ & 0 & 0,26 & 1,34 & $-0,03$ \\
\hline & $(0,80)$ & $(1,24)$ & $(-1,31)$ & $(-0,52)$ & $(0,00)$ & $(1,64)$ & $(0,86)$ & $(-0,22)$ \\
\hline \multicolumn{5}{|c|}{$\begin{array}{l}\text { Teste de significância conjunta dos coeficientes } \\
\text { referentes à parte não linear do modelo: }\end{array}$} & \multicolumn{4}{|c|}{$\begin{array}{l}\text { Teste de significância conjunta dos coeficientes } \\
\text { referentes à parte não linear do modelo: }\end{array}$} \\
\hline Equação & $\begin{array}{l}\text { Valor- } p \\
\text { assintótico }\end{array}$ & $\begin{array}{l}\text { Valor- } p \\
\text { bootstrap }\end{array}$ & & & Equação & $\begin{array}{l}\text { Valor- } p \\
\text { assintótico }\end{array}$ & $\begin{array}{l}\text { Valor- } p \\
\text { bootstrap }\end{array}$ & \\
\hline$\Delta$ Produto & 0,59 & 0,68 & & & $\Delta$ Produto & 0,72 & 0,77 & \\
\hline Inflação & 0,13 & 0,24 & & & Inflação & 0,10 & 0,21 & \\
\hline$\Delta$ Câmbio & 0,53 & 0,68 & & & $\Delta$ Câmbio & 0,22 & 0,34 & \\
\hline$\triangle$ SELIC & 0,00 & 0,00 & & & $\Delta$ SELIC & 0,08 & 0,16 & \\
\hline Modelo vetorial & 0,00 & 0,03 & & & Modelo vetorial & 0,00 & 0,24 & \\
\hline
\end{tabular}

Elaboração dos autores.

Notas:

1) Estimativas obtidas por mínimos quadrados ordinários, condicionadas aos valores de $\gamma$ e c.

2) As estatísticas-teste referentes à significância da parte não linear das equações e do modelo vetorial foram construídas com a utilização do procedimento de White para estimativa da matriz de covariância.

3) Os valores- $p$ bootstrap foram obtidos com base em 1000 replicações do modelo linear.

4) Os valores em parênteses referem-se às estatísticas $t$. 
Figura 1: Datação dos regimes para o Modelo 1 (variável de transição: $\Delta 12$ Produção Industrial $t-2$ ).

thy(t-2)

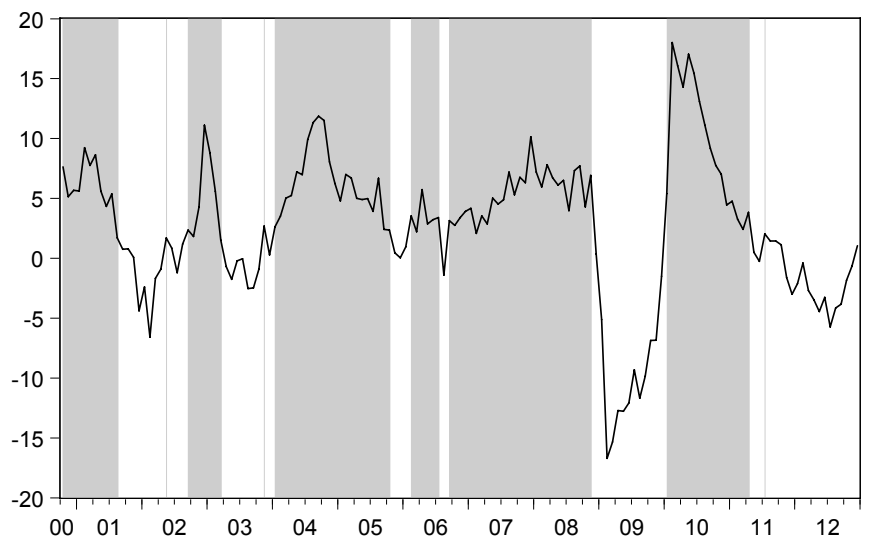

Elaboração dos autores.

Região escura $=$ regime de alto crescimento (acima de $1,5 \%$ em 12 meses).

Por fim, apresentamos nas figuras 1 e 2 a datação dos regimes de cada um dos modelos. No modelo 1 , os regimes de alto crescimento (variação em doze meses da produção industrial superior a 1,5\%) prevaleceram nos anos de 2001, 2004 a 2005, 2006 a 2008 e 2010. No modelo 2, os regimes de alta inflação, caracterizados por variações em doze meses superiores a 5,0\%, predominaram entre 2001 e 2006, 2009 e $2011-2012$.

Figura 2: Datação dos regimes para o Modelo 2 (variável de transição: Inflação(12m)t - 4).

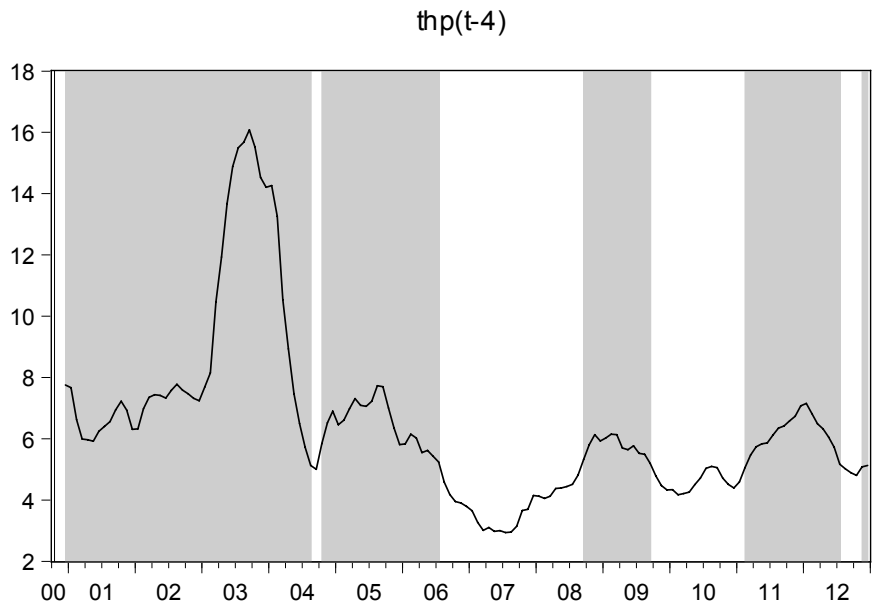

Elaboração dos autores

Região escura $=$ regime de alta inflação (acima de $5 \%$ em 12 meses). 


\section{RESULTADOS DAS FUNÇÕES DE RESPOSTA A IMPULSO}

A construção das funções de resposta a impulso (FRIs) para o modelo LSTVAR seguiu o procedimento apresentado por Koop et alii (1996). Como mencionado anteriormente, o objetivo é verificar se existem evidências de assimetrias nas respostas do produto e da inflação aos choques na SELIC. Nesta seção, serão apresentadas uma breve descrição da metodologia utilizada e os resultados das FRIs para o produto e inflação. Seguindo a notação de Koop et alii (1996), uma FRI generalizada pode ser expressa por:

$$
G I_{Y}\left(n, u_{t}, \pi_{t-1}\right)=E\left[Y_{t+n} \mid u_{t}, \pi_{t-1}\right]+E\left[Y_{t+n} \mid \pi_{t-1}\right], n=0,1, \ldots
$$

sendo: $Y$ o vetor de variáveis para o qual se deseja construir a função, $n$ o horizonte de previsão, $u_{t}$ o choque gerador da resposta, $\pi_{t-1}$ a "história" ou valores iniciais das variáveis no modelo, $E[\cdot]$ o operador da esperança matemática.

Em um modelo vetorial linear, a função de resposta a impulso é invariante em $\pi_{t-1}$, ou seja, não depende dos valores passados das variáveis. Sendo assim, $\pi_{t-1}$ pode ser zerado para traçar o cenário de referência ou baseline. No caso de um modelo não linear, a construção do cenário baseline é mais complexa. A FRI é condicionada à $\pi_{t-1}$, que pode assumir valores específicos ou ser tratada como variável aleatória. Outra diferença importante é que, na FRI obtida para um modelo linear, a trajetória esperada de $Y$ dado um choque em $t$, condicional aos choques futuros, é igual à trajetória de $Y$ quando estes mesmos choques são tomados em seus respectivos valores esperados. Ou seja, sendo $\left\{Y_{t+n}\right\}_{n=1}^{\infty}$ a sequência que define a trajetória de $Y$ dado um choque $u$ ' em $t$ e $\left\{u_{t+n+1}\right\}_{n=1}^{\infty}$ a sequência de choques futuros, para o caso linear nota-se que:

$$
E\left(\left\{Y_{t+n}\right\}_{n=1}^{\infty} \mid\left\{u_{t+n+1}\right\}_{n=1}^{\infty}\right)=\left\{Y_{t+n}\right\}_{n=1}^{\infty}+E\left(\left\{u_{t+n+1}\right\}_{n=1}^{\infty}\right)
$$

Logo, pode ser convenientemente supor que os choques futuros são iguais a zero. Todavia, não é o que ocorre com os modelos não lineares. Nestes, os choques futuros devem ser retirados de alguma distribuição e seus valores médios obtidos através de um grande número de repetições deste processo.

Por fim, destaca-se o fato de que, nos modelos lineares, a FRI é necessariamente simétrica na magnitude do choque. No caso de modelos não lineares, isso não pode ser garantido a priori.

Nota-se, então, que a utilização de modelos vetoriais não lineares permite testar diretamente o comportamento assimétrico das FRIs, o que não é possível nos modelos lineares. Assim, serão testadas as seguintes formas de assimetria nas respostas do produto e da inflação a choques monetários:

i Choques contracionistas têm efeitos distintos (em módulo) de choques expansionistas?

ii O estado do sistema (fase do ciclo de negócios, alta ou baixa inflação) afeta o ajustamento das variáveis frente a choques de mesma magnitude e sinal?

iii A resposta normalizada de choques de magnitudes diferentes é assimétrica?

\subsection{Procedimentos utilizados}

A metodologia utilizada para a construção da FRI não linear é baseada no procedimento apresentado em Koop et alii (1996) e Weise (1999), que consiste em calcular a FRI através de técnicas de Monte Carlo. ${ }^{23}$ 0 processo segue as seguintes etapas:

1. Escolher a "história" $\pi_{t-i}^{r}$, que são os valores efetivos assumidos pelas variáveis endógenas defasadas em uma determinada data;

\footnotetext{
${ }^{23}$ Ver Koop et alii (1996), páginas 135 a 137, e Weise (1999), apêndice, para maiores detalhes.
} 
2. Escolher uma sequência de choques $u_{t+n}^{b}$ (com dimensão $k$ ), $n=0,1, \ldots, q$. Estes choques são construídos com a utilização dos resíduos estimados do modelo. Como, por suposição, admitese que os choques tem distribuição conjunta, se o choque do período $t$ for sorteado, todos os $k$ resíduos para este período serão coletados.

3. Usando $\pi_{t-i}^{r}$ e $u_{t+n}^{b}$, simula-se a evolução das realizações de $y_{t+n}$ para $q+1$ períodos. $O$ resultado é o cenário baseline $Y_{t-n}\left(\pi_{t-i}^{r}, u_{t+n}\right), n=0,1, \ldots, q$.

4. Substituir $u_{i 0}$ para o $i 0$ elemento de $u_{t+n}^{b}$ e simular a evolução das realizações de $y_{t+n}$ para $q+1$ períodos. O resultado é a trajetória de $Y_{t-n}\left(u_{i 0}, \pi_{t-i}^{r}, u_{t+n}\right), n=0,1, \ldots, q$.

5. Repetir as etapas 2 a 4 por $B$ vezes.

6. Repetir as etapas 2 a 5 por $R$ vezes e calcular a média da FRI: ${ }^{24}$

$$
Y_{t-n}^{a}\left(u_{i 0}\right)=\frac{Y_{t+n}\left(u_{i 0}, \pi_{t-1}^{r}, u_{t+n}^{b}\right)-Y_{t+n}\left(\pi_{t-1}^{r}, u_{t+n}^{b}\right)}{B R}
$$

ou a mediana:

$$
Y_{t-n}^{r n}\left(u_{i 0}\right)=\text { mediana }\left\lfloor Y_{t+n}\left(u_{i 0}, \pi_{t-1}^{r}, u_{t+n}^{b}\right)-Y_{t+n}\left(\pi_{t-1}^{r}, u_{t+n}^{b}\right)\right\rfloor
$$

onde $u_{i 0}$ é um choque no período $t=0$, para a $i$-ésima variável de $Y$.

Utilizando basicamente os mesmos procedimentos de Weise (1999), foi possível construir estimativas para as respostas da inflação medida pelo IPCA e do crescimento do produto aos choques na SELIC. É importante ressaltar que a presença de heteroscedasticidade na distribuição dos resíduos depois do período $t=0$ é controlada no processo. A heteroscedasticidade na relação contemporânea não é controlada, pois o ordenamento das variáveis ${ }^{25}$ no modelo LSTVAR supõe que os choques monetários não afetam o crescimento do produto e a inflação em $t=0$. Mudanças no ordenamento das variáveis mudaram muito pouco os resultados das FRIs.

\subsection{Resultados}

A tabela 5 mostra a resposta total acumulada em 24 meses da inflação e do crescimento do produto para choques monetários distintos em sinais e magnitudes, e em diferentes estados do sistema. Para avaliar assimetrias de magnitudes, os choques de 1 ponto percentual $(1,0 \mathrm{pp})$ foram normalizados, dividindo-se a resposta total acumulada em 24 meses por dois a fim de gerar as respostas para choques de meio ponto percentual (0,5pp).

De maneira geral, o modelo 1 (threshold no crescimento do produto) apresenta evidências de que tanto o crescimento do produto como a inflação respondem assimetricamente aos choques na SELIC. ${ }^{26}$ O mesmo ocorre no modelo 2 (threshold na inflação).

\footnotetext{
${ }^{24}$ Nas simulações foram utilizados os valores $B=100$ e $R=100$, assim como em Weise (1999).

${ }^{25} \mathrm{O}$ ordenamento utilizado foi: crescimento do produto, inflação, variação percentual da taxa de cambio nominal e variação da taxa SELIC. Esse ordenamento foi adotado para considerar os impactos contemporâneos da taxa de cambio na SELIC e, por conseguinte, considerar este efeito na identificação dos choques monetários.

${ }^{26}$ Choques positivos e negativos na SELIC são interpretados como contracionistas e expansionistas, respectivamente.
} 
Tabela 5: Resposta acumulada (em \%) após 24 meses da inflação e do crescimento do produto para choques distintos na SELIC (em sinal e magnitude) em diferentes estados do sistema.

\begin{tabular}{lccccccccc}
\hline & \multicolumn{3}{c}{ Choque de 0,5pp } & \multicolumn{2}{c}{ Choque de 1,0pp (normalizado) } \\
Modelo Estado & \multicolumn{2}{c}{ Crescimento } & \multicolumn{2}{c}{ Inflação } & \multicolumn{2}{c}{ Crescimento } & \multicolumn{2}{c}{ Inflação } \\
& $\begin{array}{c}\text { Choque } \\
\text { contr. }\end{array}$ & $\begin{array}{c}\text { Choque } \\
\text { exp. }\end{array}$ & $\begin{array}{c}\text { Choque } \\
\text { contr. }\end{array}$ & $\begin{array}{c}\text { Choque } \\
\text { exp. }\end{array}$ & $\begin{array}{c}\text { Choque } \\
\text { contr. }\end{array}$ & $\begin{array}{c}\text { Choque } \\
\text { exp. }\end{array}$ & $\begin{array}{c}\text { Choque } \\
\text { contr. }\end{array}$ & $\begin{array}{c}\text { Choque } \\
\text { exp. }\end{array}$ \\
\hline $\begin{array}{l}\text { Modelo Linear } \\
\text { Modelo 1 }\end{array}$ & $-0,95$ & 0,95 & 0,44 & $-0,44$ & $-0,91$ & 0,91 & 0,39 & $-0,39$ \\
Alto crescimento & 0,58 & 2,14 & 0,57 & 0,50 & 0,11 & 1,52 & 0,41 & 0,33 \\
Baixo crescimento & $-2,04$ & $-0,53$ & $-0,45$ & $-0,57$ & $-1,60$ & $-0,22$ & $-0,38$ & $-0,45$ \\
Modelo 2 & & & & & & & & \\
$\quad$ Alta inflação & 0,41 & 1,07 & 0,21 & 0,91 & 0,10 & 0,89 & 0,00 & 0,77 \\
Baixa inflação & $-1,16$ & $-0,40$ & $-0,90$ & $-0,20$ & $-0,83$ & $-0,22$ & $-0,75$ & $-0,04$ \\
\hline
\end{tabular}

Elaboração dos autores.

Nota: choque contr. $=$ choque monetário contracionista, choque exp. = choque monetário expansionista.

Observando a tabela 5 e as figuras 3 e 5, pode-se concluir que, no caso do modelo 1, existe uma evidência de que choques monetários contracionistas e expansionistas têm efeitos assimétricos sobre o crescimento do produto e a inflação. Se o sistema encontra-se em um estado de baixo crescimento, os choques contracionistas reduzem o crescimento e a inflação, com maior efeito acumulado sobre a primeira variável. Se o regime for de alto crescimento, os choques contracionistas de 0,5pp provocam elevações naquelas variáveis (figura 3). No entanto, se o choque contracionista for de 1,0pp (figura 5), o crescimento do produto cai por 18 meses mesmo naquele regime, o que aumenta a probabilidade de uma mudança de estado para um regime de baixo crescimento (cenário no qual mesmo um choque contracionista de 0,5 pp provoca redução da inflação). Por outro lado, os choques expansionistas provocam elevação do crescimento e da inflação principalmente no regime de alto crescimento. No regime de baixo crescimento, as FRIs mostram que um choque expansionista de 1,0pp aumenta o crescimento temporariamente (por cerca 15 meses), ainda que em pequena magnitude, sem provocar elevação da inflação.

Os resultados descritos acima diferem daqueles encontrados em Aragón e Portugual (2009), ${ }^{27}$ que mostraram evidências de que choques monetários positivos e negativos geram efeitos assimétricos sobre o crescimento do produto apenas em períodos de expansão econômica (situação em que, segundo os mesmos autores, uma política contracionista seria mais efetiva). Por outro lado, as FRIs aqui apresentadas mostram que não existe evidência de assimetria significativa entre os choques monetários contra cíclicos, resultado semelhante ao encontrado naquele estudo.

Quando a variável de transição é a variação percentual do IPCA (modelo 2), caracterizando regimes de alta e baixa inflação, os resultados das FRIs (figuras 4 e 6) se mostraram similares aos obtidos com o modelo 1. Choques expansionistas elevam o crescimento do produto e a inflação principalmente no regime de alta inflação. No regime de baixa inflação, apenas choques expansionistas de 1,0pp elevam 0 crescimento e a inflação temporariamente e em pequena magnitude (figura 6). Por outro lado, choques contracionistas se mostraram mais eficazes no regime de inflação baixa, e provocaram, no regime de alta inflação, respostas negativas em relação ao cenário baseline apenas quando a magnitude foi de 1,0 pp.

\footnotetext{
27'́ importante ressaltar que, além da diferença de metodologia, os autores utilizaram dados do período de 1995 a 2006.
} 
Figura 3: Resposta acumulada (em \%) após 24 meses do crescimento da produção industrial e da inflação para um choque de 0,5 pp na SELIC, em relação ao cenário baseline - Modelo 1.

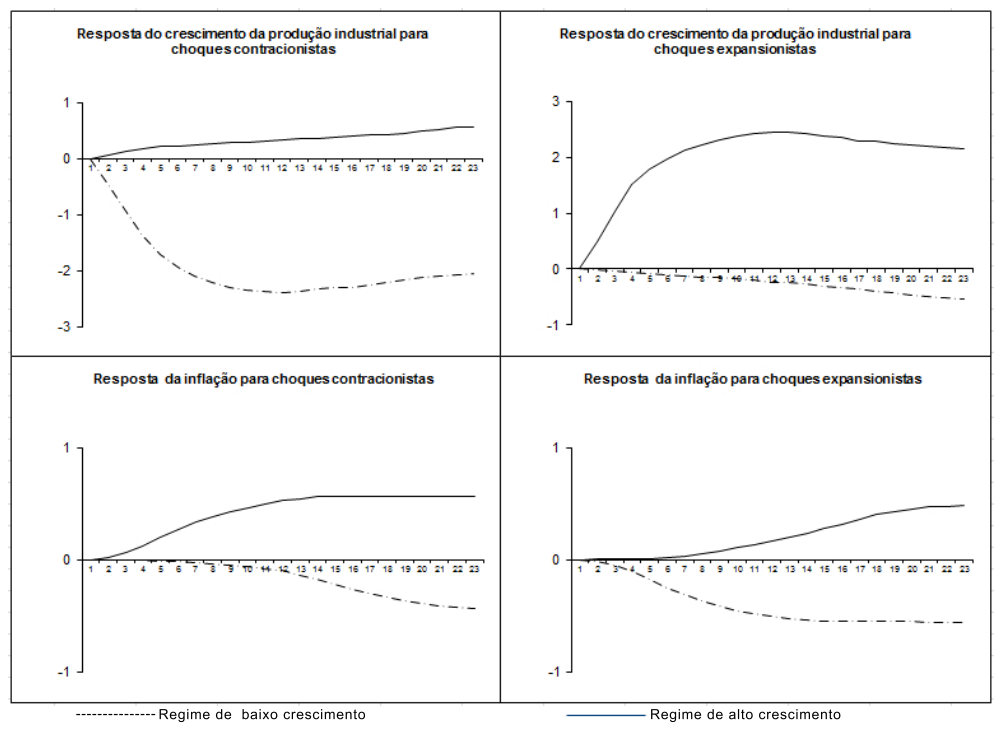

Fonte: Elaboração própria.

Figura 4: Resposta acumulada (em \%) após 24 meses do crescimento da produção industrial e da inflação para um choque de 0,5 pp na SELIC, em relação ao cenário baseline - Modelo 2.

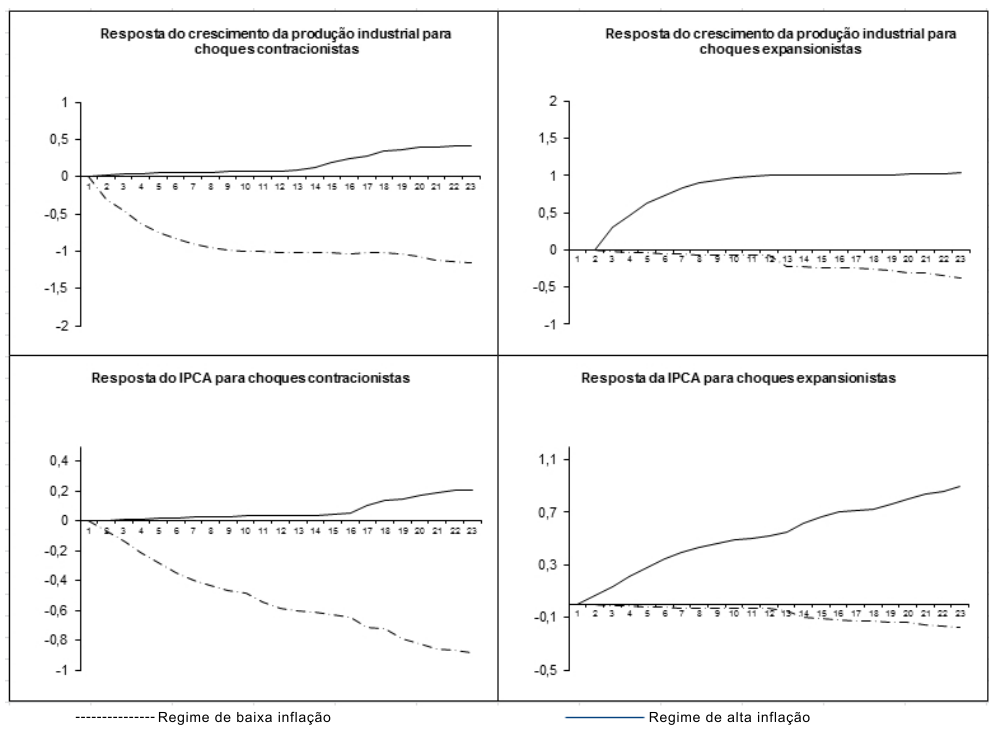

Fonte: Elaboração própria. 
Figura 5: Resposta acumulada (em \%) após 24 meses do crescimento da produção industrial e da inflação para um choque de 1,0 pp na SELIC, em relação ao cenário baseline - Modelo 1.

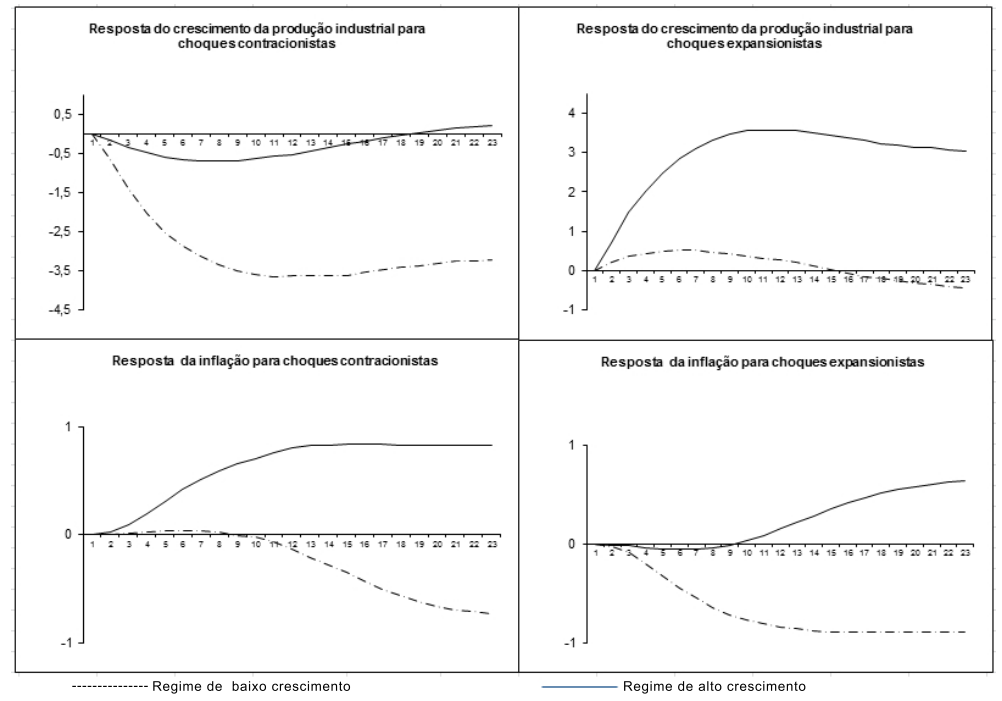

Fonte: Elaboração própria.

Figura 6: Resposta acumulada (em \%) após 24 meses do crescimento da produção industrial e da inflação para um choque de 1,0 pp na SELIC, em relação ao cenário baseline - Modelo 2.

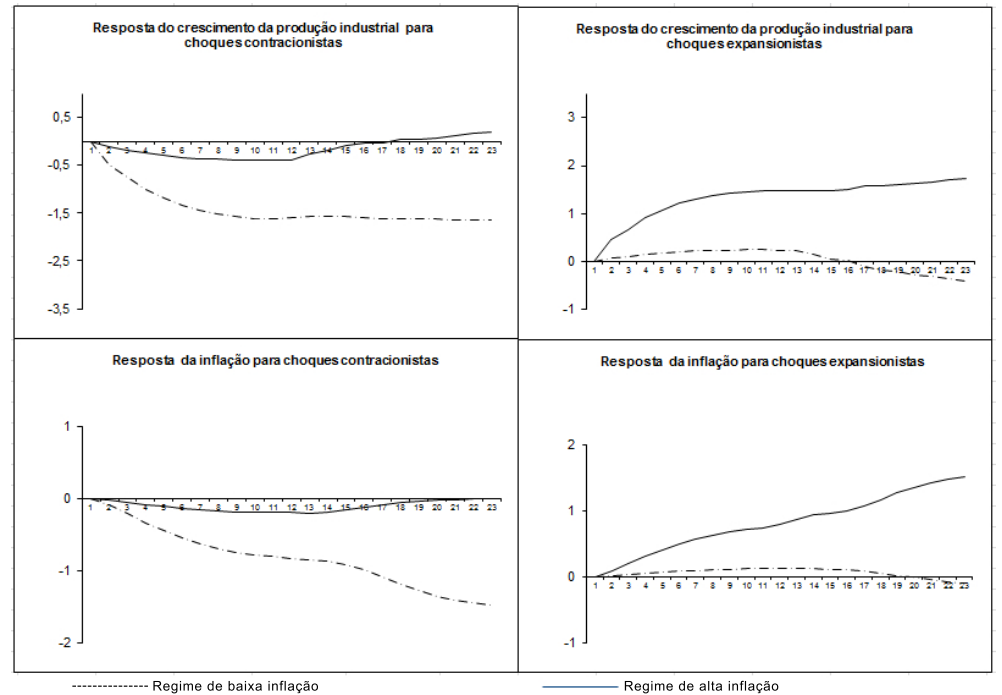

Fonte: Elaboração própria. 
Em síntese, as FRIs mostram que os choques contra cíclicos têm impacto limitado para reverter o estado da economia, independentemente da variável de transição utilizada. No entanto, a depender da magnitude do choque, o resultado qualitativo muda. Ou seja, para choques contra cíclicos de 0,5pp as FRIs mostram respostas próximas a zero e/ou com um efeito puzzle em ambas as variáveis. Quando o choque é de 1,0pp, o efeito puzzle diminui ou desaparece. Como já mencionado, esse aspecto é importante, pois é um indicativo de que o modelo gera resultados compatíveis com a ideia de que os choques monetários podem afetar o ciclo econômico. Ademais, como é possível notar pela tabela 5 , choques pró-cíclicos de pequena magnitude têm, em termos proporcionais, eficácia ligeiramente maior do que choques pró-cíclicos de grande magnitude.

Os resultados obtidos mostram evidências de não linearidade nos efeitos de choques monetários para o caso da economia brasileira no período recente, além de serem parecidos para as distintas variáveis de transição utilizadas. $O$ fato de os regimes de alto e baixo crescimento não coincidirem necessariamente com os regimes de alta e baixa inflação pode evidenciar a existência de mais de dois regimes. Ou seja, o impacto dos choques monetários sobre o crescimento e a inflação parece depender tanto do ritmo de crescimento da economia como do comportamento recente da inflação.

\section{CONSIDERAÇÕES FINAIS}

O presente trabalho investigou a existência de efeitos assimétricos de choques monetários sobre o produto e a inflação no Brasil para o período entre julho de 1999 e dezembro de 2012. Seguindo a metodologia de Weise (1999), a estratégia de investigação envolveu a análise de funções de resposta a impulso geradas a partir de um modelo vetorial não linear de transição suave. Foram consideradas especificações com duas variáveis de transição distintas - variação da produção industrial e inflação.

O principal resultado evidenciado foi que a existência de assimetrias nas respostas do produto e da inflação a choques monetários expansionistas e contracionistas está condicionada à alternância de regimes, medidos pelo crescimento da produção industrial ou pela inflação. Assim, choques monetários expansionistas aumentam significativamente o crescimento do produto e a inflação apenas nos regimes de maiores crescimento ou inflação, e têm efeito pequeno ou oposto ao esperado (efeitos puzzle) sobre as mesmas variáveis nos regimes de crescimento ou inflação menores. Analogamente, choques monetários contracionistas reduzem o produto e a inflação de forma significativa apenas em regimes onde 0 crescimento ou a inflação são menores, sendo seu impacto menor ou oposto ao esperado nos regimes de maiores crescimento ou inflação. Ou seja, choques pró-cíclicos têm grande impacto sobre o produto e a inflação, enquanto os choques contra cíclicos afetam pouco essas duas variáveis ou o fazem na direção oposta à esperada. Ademais, a propagação dos choques nas duas fases da política contra cíclica (pró-cíclica) - expansionista nos baixos crescimento ou inflação e contracionista no alto crescimento ou alta inflação (contracionista no baixo crescimento ou baixa inflação e expansionista no alto crescimento ou alta inflação) - é praticamente simétrica.

Também foram constatadas evidências de assimetria em relação à magnitude dos choques. Quanto aos impulsos monetários pró-cíclicos, choques na SELIC de 0,5 ponto percentual (menor magnitude) se mostraram proporcionalmente mais efetivos do que choques de 1 ponto percentual (maior magnitude) no horizonte de 24 meses, tanto sobre o crescimento do produto quanto sobre a inflação. Já no caso de uma política monetária contra cíclica, as respostas após 24 meses dos preços e do produto a choques de 0,5 pp apresentaram efeitos puzzle, acentuando ligeiramente o ciclo ao invés de revertê-lo. Porém, esses efeitos puzzle são substancialmente reduzidos ou até anulados na resposta a choques de 1 ponto percentual para o horizonte de 24 meses. Contudo, isso não significa que os choques contra cíclicos grandes são sem efeito, pois, em horizontes temporais mais curtos, o efeito médio dos choques grandes sobre produto e preços apresenta os sinais esperados pela teoria e, embora as respostas sejam próximas de zero, aumentam a probabilidade de o sistema mudar de estado e, com isso, elevar a potência da política desejada. 
Com o crescimento do produto como variável de transição, as evidências obtidas são condizentes com as teorias que explicam a assimetria pelos canais de transmissão da moeda à demanda agregada, especialmente na vertente que destaca o papel da incerteza. $O$ fato de a rigidez de preços e quantidades apontar na mesma direção - rígidos a choques anticíclicos e flexíveis a choques pró-cíclicos - contradiz as teorias de oferta agregada convexa e custos de menu, mas é condizente com mudanças cíclicas no canal de transmissão da moeda para a demanda agregada. Com a inflação como variável de transição, a interpretação pode ser similar, pois também neste caso os resultados confrontam o previsto nas teorias de convexidade da oferta e custos de menu.

O resultado obtido é diferente do encontrado usualmente para os EUA e alguns países Europeus em relação ao produto, de que a política monetária é muito eficaz nas recessões e pouco nas expansões, qualquer que seja a direção do choque. Weise (1999), que testa para os EUA também o impacto sobre os preços e com a metodologia que foi aplicada no presente estudo ao Brasil, encontra evidências favoráveis à convexidade da curva de oferta. Outros estudos, embora não testem efeitos sobre preços, sugerem que o acelerador financeiro poderia explicar a eficácia maior da política monetária na recessão. Contudo, a teoria do acelerador financeiro apenas prevê uma amplificação dos efeitos da política monetária. Para que ocorra esse tipo de assimetria, é necessário que a influência negativa do ambiente desfavorável sobre a oferta de liquidez de agentes financeiros seja mais intensa na crise que a influência do ambiente favorável na expansão. Os resultados obtidos no presente estudo não requerem essa hipótese. Por outro lado, necessitam que o canal de transmissão da moeda para a demanda agregada seja fraco para choques monetários anticíclicos e forte para os que acentuam o ciclo, o que não é uma implicação das teorias de acelerador financeiro.

Porém, tais resultados se encaixam perfeitamente em outra vertente teórica sobre assimetria no canal de transmissão da moeda à demanda agregada, a que destaca o efeito da incerteza quanto ao ambiente econômico na disposição a gastar e preferência pela liquidez dos agentes. A política monetária contra cíclica é enfraquecida pela incerteza na fase baixa do ciclo e pelo otimismo exacerbado na fase de ascensão, enquanto os choques pró-cíclicos acentuam ainda mais ambos os estados de espírito nas duas fases do ciclo. Esse raciocínio pode ser estendido para o caso da inflação como variável de transição: a inflação alta fomenta um ambiente de incerteza, que reduz o efeito da política monetária contracionista pela falta de confiança dos agentes, enquanto a inflação baixa gera um ambiente otimista, em que a política monetária pode ser mais expansionista sem acentuar a inflação.

Para a discussão das implicações sobre o regime brasileiro de metas para a inflação, cabe recordar que o modelo adotado avalia efeitos de choques monetários "puros", que são aqueles identificados no modelo VAR como exógenos. Ou seja, não se referem à resposta induzida pela função de reação do Banco Central ao hiato do produto, aos desvios da meta de inflação e ao câmbio, mas sim a "surpresas", variações imprevistas na SELIC. Nesse contexto, é possível apontar ao menos três implicações resultantes dos efeitos assimétricos dos choques monetários no Brasil. Em regimes de alta inflação, a estratégia de reduzir a inflação por meio de elevações da taxa de juros acima do esperado geralmente implica em aumentos substanciais da taxa de juros, com efeito pequeno sobre a inflação. Ademais, sob regimes de alto crescimento, as tentativas de acelerar o crescimento ainda mais através de choques monetários expansionistas têm êxito, mas ao custo de uma elevação da taxa de inflação. Por fim, os resultados obtidos mostram que, em regimes de baixo crescimento, reduções inesperadas da taxa SELIC não teriam custos inflacionários consideráveis. Ou seja, fases recessivas da economia brasileira poderiam ser aproveitadas para reduzir a taxa sem levar a uma aceleração inflacionária. 


\section{BIBLIOGRAFIA}

Aragón, E. \& Portugual, M. (2009). Asymmetric Effects of Monetary Policy in Brazil. Estudos Econômicos, 39(2):277-300.

Arquete, L. \& Jayme Jr., F. (2003). Política Monetária, Preços e Produto no Brasil (1994-2002): Uma Aplicação de Vetores Auto regressivos. In Anais do XXXI Encontro Nacional de Economia.

Balke, N. (2000). Credit and Economic Activity: Credit Regimes and Nonlinear Propagation of Shocks. The Review of Economics and Statistics, 82(2):344-349.

Ball, L. \& Mankiw, N. (1994). Asymmetric Price Adjustment and Economic Fluctuations. The Economic Journal, 104:247-261.

Bernanke, B. \& Gertler, M. (1995). Inside the Black Box: The Credit Channel of Monetary Policy Transmission. Journal of Economic Perspectives, 9:27-48.

Bernanke, B., Gertler, M., \& Gilchrist, S. (1996). The Financial Accelerator and the Flight to Quality. Review of Economics and Statistics, 78:1-15.

Bernanke, B., Gertler, M., \& Gilchrist, S. (1999). Handbook of Macroeconomics 1, chapter 21, pages 13411393. The Financial Accelerator in a Quantitative Business Cycle Framework. North Holland.

Céspedes, B., Lima, E., \& Maka, A. (2008). Economic Activity in Brazil After the Real Plan: Stylized Facts from SVAR Models. Revista Brasileira de Ecônomia, 62(2):123-60.

Cover, J. (1992). Asymmetric Effects of Positive and Negative Money-Supply Shocks. Quarterly Journal of Economics, 107(4):1261-1282.

DeLong, J. \& Summers, L. (1988). How Does Macroeconomic Policy Affect Output? Brookings Papers on Economic Activity, 2:433-494.

Eitrheim, O. \& Teräsvirta, T. (1996). Testing the adequacy of smooth transition autoregressive models. Journal of Econometrics, 74:59-76.

Garcia, R. \& Schaller, H. (2002). Are the Effects of Monetary Policy Asymmetric? Economic Inquiry, 40:102-119.

Gertler, M. \& Gilchrist, S. (1994). Monetary Policy. Business Cycles, and the Behavior of Small Manufacturing Firms. The Quarterly Journal of Economics, 109(2):309-340.

Hamilton, J. (1989). A New Approach to the Economic Analysis of Nonstationary Time Series and the Business Cycle. Econometrica, 57:357-384.

Hendry, D. (1995). Dynamic Econometrics. Oxford University Press.

Hooi, S., Habibullah, M., \& Smith, P. (2008). The Asymmetric Effects of Monetary Policy in Four Asian Economies. International Applied Economics and Management Letters, 1(1):1-7.

Karras, G. (1996). Are the Output Effects of Monetary Policy Asymmetric? Evidence from a Sample of European Countries. Oxford Bulletin of Economics and Statistics, 58:267-278.

Karras, G. (2007). What Causes The Asymmetric Effects Of Monetary Policy: Size or Sign of Money-Supply Shocks? The Journal of Economic Asymmetries, 4(1):57-72.

Karras, G. \& Stokes, H. (1999). Why are the Effects of Money-Supply Shocks Asymmetric? Evidence from Prices, Consumption, and Investment. Journal of Macroeconomics, 21:713-727. 
Koop, G., Pesaran, M., \& Potter, S. (1996). Impulse Response Analysis in Nonlinear Multivariate Models. Journal of Econometrics, 74:119-147.

Lee, J. \& Strazicich, M. (2003). Minimum Lagrange Multiplier Unit Root Test with Two Structural Breaks. The Review of Economics and Statistics, 85(4):1082-1089.

Lima, E., Maka, A., \& Alves, P. (2011). Monetary Policy and Exchange Rate Shocks in Brazil: Sign Restrictions versus a New Hybrid Identification Approach. Brazilian Review of Econometrics, 31(1):97-136.

Lima, E., Maka, A., \& Mendonça, M. (2007). Monetary Policy Regimes in Brazil. Texto para Discussão 1285, Instituto de Pesquisa Econômica Aplicada - IPEA, Rio de Janeiro.

Lo, M. \& Piger, J. (2005). Is the response of output to monetary policy asymmetric? Evidence from a regime-switching coefficients model. Journal of Money, Credit and Banking, 37:865-887.

Luukkonen, R., Saikkonen, P., \& Teräsvirta, T. (1988). Testing Linearity Against Smooth Transition Autoregressive Models. Biometrika, 75:491-499.

Mendonça, M., Medrano, L., \& Sachsida, A. (2010). Efeitos da Política Monetária na Economia Brasileira: Resultados de um Procedimento de Identificação Agnóstica. Pesquisa e Planejamento Econômico, 40(3):367-394.

Moreira, A., Fiorencio, A., \& Lima, E. (1998). Os Impactos das Políticas Monetária e Cambial no Brasil Pós-Plano Real. Texto para Discussão 579, Instituto de Pesquisa Econômica Aplicada - IPEA, Rio de Janeiro.

Morgan, D. (1993). Asymmetric Effects of Monetary Policy. Federal Reserve Bank of Kansas City Economic Review, 78:21-33.

Peersman, G. \& Smets, F. (2002). Monetary Transmissions in Diverse Economies, chapter 2, pages 28-48. Are the effects of monetary policy in the euro area greater in recessions than in booms? Cambridge University Press.

Peersman, G. \& Smets, F. (2005). The Industry Effects of Monetary Policy in the Euro Area. The Economic Journal, 115:319-342.

Ravn, M. \& Sola, M. (1996). A Reconsideration of the Empirical Evidence on the Asymmetric Effects of Money-Supply Shocks: Positive vs. Negative or Big vs. Small? Center for Non-Linear Modeling in Economics - University of Aarhus. Working Paper No. 1996-4.

Ravn, M. \& Sola, M. (2004). Asymmetric Effects of Monetary Policy in the U.S.: Positive versus Negative or Big versus Small? Federal Reserve Bank of St. Louis Review, 86(5):41-60.

Rothman, P., van Dijk, D., \& Franses, P. (2001). Multivariate Star Analysis of Money Output Relationship. Macroeconomic Dynamics, 5:506-532.

Saikkonen, P. \& Lütkepohl, H. (2002). Testing for a Unit Root in a Time Series with a Level Shift at Unknown Time. Econometric Theory, 18:313-348.

Schaling, E. (2004). The non-linear Phillips curve and inflation forecast targeting. Journal of Money, Credit E Banking, 36:361-386.

Senda, T. (2001). Asymmetric Effects of Money Supply Shocks and Trend Inflation. Journal of Money, Credit, and Banking, 33(1):65-89. 
Sims, C. (1992). Interpreting the Macroeconomic Times Series Facts: The Effects of Monetary Policy. European Economic Review, 36:975-1011.

Tan, S., Habibullah, M., \& Mohamed, A. (2010). Asymmetric Effects of Monetary Policy in ASEAN-4 Economies. International Research Journal of Finance and Economics, 44:30-42.

Teräsvirta, T. (1994). Specification, Estimation, and Evaluation of Smooth Transition Autoregressive Models. Journal of the American Statistical Association, 89:208-218.

Teräsvirta, T. (2004). Applied Time Series Econometrics, chapter 6, pages 222-242. Smooth Transition Regression Modeling. Cambridge University Press.

Thoma, M. (1994). Subsample Instability and Asymmetries in Money-Income Causality. Journal of Econometrics, 64:279-306.

van Dijk, D., Teräsvirta, T., \& Franses, P. (2002). Smooth Transition Autoregressive Models A Survey of Recent Developments. Econometric Reviews, 21:1-47.

Weise, C. (1999). Asymmetric Effects of Monetary Policy: A Nonlinear Vector Autoregression Approach. Journal of Money, Credit \& Banking, 31(1):85-108. 


\section{A. APÊNDICE A - FIGURA A.1}

Figura A-1: Gráficos das séries relativas à produção industrial, variação percentual do IPCA, taxa de câmbio e taxa de juros SELIC. Período entre julho de 1999 e dezembro de 2012.
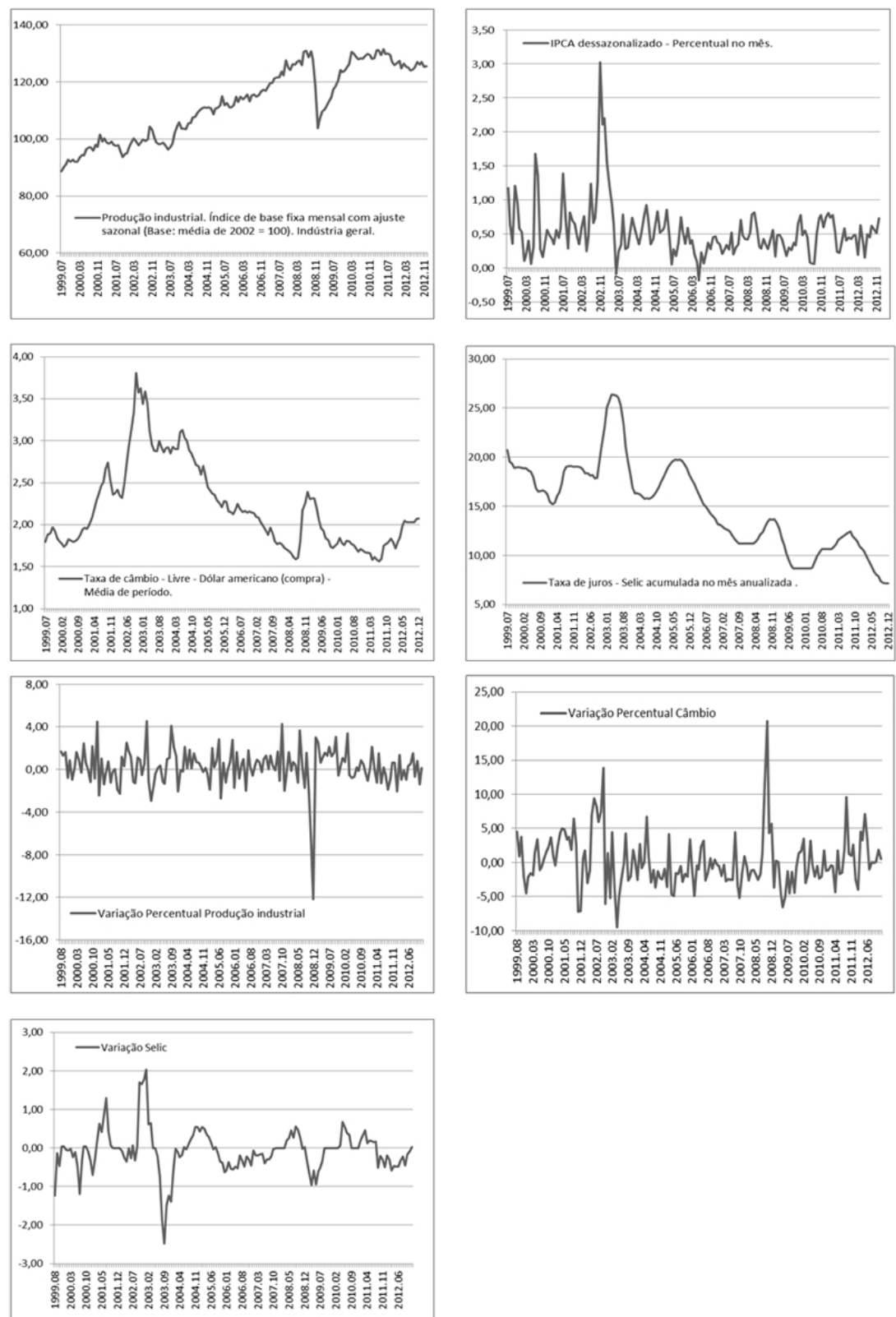

Fontes: IBGE, para Produção Industrial e Inflação IPCA; BACEN, para as taxas de câmbio e SELIC 


\section{B. APÊNDICE A2 - TABELA A.2}

Table 1: Resultados das previsões fora da amostra para o Modelo 1 (variável de transição $\Delta 12$ Produção Industrial $t-2)$. Modelo estimado com dados até dezembro de 2010.

\begin{tabular}{lcccccccc}
\hline & \multicolumn{4}{c}{ Crescimento } & \multicolumn{3}{c}{ Inflação } \\
\hline & LSTVAR & \multicolumn{3}{c}{ VAR } & & LSTVAR & \multicolumn{3}{c}{ VAR } \\
\hline \multicolumn{1}{c}{ Horizonte } & EQM & $\begin{array}{c}\text { Erro } \\
\text { Acumulado }\end{array}$ & EQM & $\begin{array}{c}\text { Erro } \\
\text { Acumulado }\end{array}$ & EQM & $\begin{array}{c}\text { Erro } \\
\text { Acumulado }\end{array}$ & EQM & $\begin{array}{c}\text { Erro } \\
\text { Acumulado }\end{array}$ \\
\hline 6 meses & 1,741 & 0,107 & 1,605 & $-0,292$ & 0,048 & 0,680 & 0,057 & 0,754 \\
12 meses & 1,603 & $-4,266$ & 1,366 & $-3,724$ & 0,032 & 0,629 & 0,040 & 0,089 \\
18 meses & 1,606 & $-8,079$ & 1,452 & $-7,751$ & 0,038 & $-0,124$ & 0,042 & $-0,782$ \\
24 meses & 1,431 & $-8,101$ & 1,322 & $-8,569$ & 0,031 & $-0,384$ & 0,034 & $-0,515$ \\
ultimos 12 meses & 1,259 & $-3,758$ & 1,277 & $-4,747$ & 0,029 & $-0,991$ & 0,028 & $-0,572$ \\
\hline
\end{tabular}

Elaboração dos autores.

\section{APÊNDICE A3 - TABELA A.3}

Table 2: Resultados das previsões fora da amostra para o Modelo 2 (variável de transição Inflação (12m) $t-4)$. Modelo estimado com dados até dezembro de 2010.

\begin{tabular}{lcccccccc}
\hline & \multicolumn{4}{c}{ Crescimento } & \multicolumn{4}{c}{ Inflação } \\
\hline & LSTVAR & \multicolumn{3}{c}{ VAR } & & LSTVAR & \multicolumn{3}{c}{ VAR } \\
\hline \multicolumn{1}{c}{ Horizonte } & EQM & $\begin{array}{c}\text { Erro } \\
\text { Acumulado }\end{array}$ & EQM & $\begin{array}{c}\text { Erro } \\
\text { Acumulado }\end{array}$ & EQM & $\begin{array}{c}\text { Erro } \\
\text { Acumulado }\end{array}$ & EQM & $\begin{array}{c}\text { Erro } \\
\text { Acumulado }\end{array}$ \\
\hline 6 meses & 1,558 & $-1,039$ & 1,605 & $-0,292$ & 0,034 & 0,606 & 0,057 & 0,754 \\
12 meses & 1,489 & $-5,875$ & 1,366 & $-3,724$ & 0,023 & 0,572 & 0,040 & 0,089 \\
18 meses & 1,612 & $-10,762$ & 1,452 & $-7,751$ & 0,028 & 0,184 & 0,042 & $-0,782$ \\
24 meses & 1,500 & $-12,036$ & 1,322 & $-8,569$ & 0,025 & 0,406 & 0,034 & $-0,515$ \\
ultimos 12 meses & 1,511 & $-5,930$ & 1,277 & $-4,747$ & 0,027 & $-0,188$ & 0,028 & $-0,572$ \\
\hline
\end{tabular}

